\title{
Retinoid X Receptor: Cellular and Biochemical Roles of Nuclear Receptor with a Focus on Neuropathological Involvement
}

\author{
Samridhi Sharma ${ }^{1}$ (1) - Ting Shen ${ }^{1} \cdot$ Nitin Chitranshi ${ }^{1} \cdot$ Veer Gupta $^{2}$. Devaraj Basavarajappa ${ }^{1}$. Soumalya Sarkar ${ }^{1}$. \\ Mehdi Mirzaei $^{1} \cdot$ Yuyi You ${ }^{1,3}$. Wojciech Krezel ${ }^{4}$. Stuart L. Graham ${ }^{1,3}$. Vivek Gupta ${ }^{1}$
}

Received: 19 August 2021 / Accepted: 21 December 2021 / Published online: 11 January 2022

(c) The Author(s) 2021

\begin{abstract}
Retinoid X receptors (RXRs) present a subgroup of the nuclear receptor superfamily with particularly high evolutionary conservation of ligand binding domain. The receptor exists in $\alpha, \beta$, and $\gamma$ isotypes that form homo-/heterodimeric complexes with other permissive and non-permissive receptors. While research has identified the biochemical roles of several nuclear receptor family members, the roles of RXRs in various neurological disorders remain relatively under-investigated. RXR acts as ligand-regulated transcription factor, modulating the expression of genes that plays a critical role in mediating several developmental, metabolic, and biochemical processes. Cumulative evidence indicates that abnormal RXR signalling affects neuronal stress and neuroinflammatory networks in several neuropathological conditions. Protective effects of targeting RXRs through pharmacological ligands have been established in various cell and animal models of neuronal injury including Alzheimer disease, Parkinson disease, glaucoma, multiple sclerosis, and stroke. This review summarises the existing knowledge about the roles of RXR, its interacting partners, and ligands in CNS disorders. Future research will determine the importance of structural and functional heterogeneity amongst various RXR isotypes as well as elucidate functional links between RXR homo- or heterodimers and specific physiological conditions to increase drug targeting efficiency in pathological conditions.
\end{abstract}

Keywords Nuclear receptors $\cdot$ Retinoid X receptor $(\mathrm{RXR}) \cdot$ Lipid X receptor $(\mathrm{LXR}) \cdot$ Peroxisome proliferator-activated receptor (PPAR) · Nuclear receptor-related 1 (Nurr1) · Heterodimerisation · Neuronal stress · Neuroinflammation ·

Neuroprotection · Glucose metabolism · Lipid metabolism ligand · Endogenous ligands · Exogenous ligands · Bexarotene $\cdot$ Glaucoma $\cdot$ Alzheimer disease $\cdot$ Parkinson disease $\cdot$ Multiple sclerosis $\cdot$ Stroke

Samridhi Sharma and Ting Shen are equal first authors

Stuart L Graham and Vivek Gupta are equal senior authors

\section{Samridhi Sharma}

samridhi.sharma@mq.edu.au

$\triangle$ Vivek Gupta

vivek.gupta@mq.edu.au

1 Macquarie Medical School, Faculty of Medicine, Health and Human Sciences, Macquarie University, Sydney, NSW, Australia

2 School of Medicine, Deakin University, Melbourne, VIC, Australia

3 Save Sight Institute, University of Sydney, Sydney, NSW, Australia

4 Institut de Génétique Et de Biologie Moléculaire Et Cellulaire, INSERM U1258, CNRS UMR 7104, Unistra, 67404 Illkirch-Graffenstaden, France

\section{Abbreviations}

APP

Akt

AXL

BAD

bFGF

C1q

CD36

ChIP

CRBPII

CYP19

EEPD1

eNOS

FoxO3A

GADD153

IL-1 $\beta$

iNOS
Amyloid precursor protein

Protein kinase B

A receptor tyrosine kinase

BCL2-associated agonist of cell death

Basic fibroblast growth factor

Complement component $1 \mathrm{q}$

Cluster of differentiation 36

Chromatin immunoprecipitation

Cellular retinol binding protein type II

Cytochrome P450, family 19

Endonuclease/exonuclease/phosphatase family domain-containing protein 1

Endothelial nitric oxide synthase

Forkhead box protein $\mathrm{O} 3$

Growth arrest and DNA damage 153Ib-1a: ionised calcium-binding adapter molecule Interleukin- $1 \beta$

Inducible nitric oxide synthase 


\begin{tabular}{|c|c|}
\hline LDLR & Low-density lipoprotein receptor \\
\hline LINGO & $\begin{array}{l}\text { Leucine-rich repeat and immunoglobin-like } \\
\text { domain-containing protein } 1\end{array}$ \\
\hline MAPK & Mitogen-activated protein kinase \\
\hline MerTK & $\begin{array}{l}\text { Myeloid-epithelial-reproductive protein } \\
\text { tyrosine kinase }\end{array}$ \\
\hline MGFE8 & Milk fat globule epidermal growth factor \\
\hline MnSOD & Manganese superoxide dismutase \\
\hline NF- $\kappa B$ & $\begin{array}{l}\text { Nuclear factor kappa light chain enhancer o } \\
\text { activated B cells }\end{array}$ \\
\hline p-PERK & $\begin{array}{l}\text { Phosphorylated extracellular-signal-regu- } \\
\text { lated kinase }\end{array}$ \\
\hline PGC-1 & $\begin{array}{l}\text { Peroxisome proliferator-activated receptor } \\
\text { gamma coactivator } 1\end{array}$ \\
\hline PS1 & Presenilin1 \\
\hline PTX3 & Pentraxin 3 \\
\hline Sema3A & Semaphorin $3 \mathrm{~A}$ \\
\hline SIRT6 & Sirtuin 6 \\
\hline SNP & Single-nucleotide polymorphism \\
\hline SREBF2 & $\begin{array}{l}\text { Sterol regulatory element binding transcrip- } \\
\text { tion factor } 2\end{array}$ \\
\hline STAT3 & $\begin{array}{l}\text { Signal transducer and activator of transcrip- } \\
\text { tion } 3\end{array}$ \\
\hline TGM2 & Tissue transglutaminase \\
\hline TREM2 & $\begin{array}{l}\text { Triggering receptor expressed on myeloid } \\
\text { cells } 2\end{array}$ \\
\hline UCP2 & Uncoupling protein 2 \\
\hline VEGF & Vascular endothelial growth factor \\
\hline
\end{tabular}

\section{Introduction}

Most cells express receptor proteins that recognise and respond to diverse internal and external stimuli. By acting as transcription factors, the nuclear receptors play a central role in regulating many biological processes, ranging from gene expression, maintenance of intracellular metabolic and physiological balance to cellular differentiation and development [1]. The nuclear receptor superfamily is comprised of 48 members of receptor/proteins, and amongst these, retinoid $\mathrm{X}$ receptor (RXR) is one of the most intriguing member that plays a role in regulating diverse physiological and disease processes [2]. RXRs are involved in transcriptional regulation by forming obligate heterodimers with multiple nuclear receptors, although activity of homodimer and homotetramers has also been suggested [3, 4]. Due to this inherent capability to engage with different nuclear receptors, RXR and its partners orchestrate pleiotropic physiological and molecular roles in cell and tissue-specific manner [2, 3]. Studies attempting to unravel complexity of the RXRdependent transcriptional regulation have demonstrated RXR's ability to regulate transcription in a ligand-dependent or ligand-independent manner $[5,6]$. This dual regulatory feature effectively means that RXR partners can be divided into permissive and non-permissive heterodimers [6]. The heterodimer activation induced by RXR agonist is classified under the permissive category and a non-permissive category corresponding to those heterodimers which are activated by ligands specific to the other nuclear receptors that partner with RXR, participating in a silent or supportive manner [6]. Permissive partner heterodimerisation in which both RXR and its partner ligand are simultaneously activated confers a synergistic biological response, and such coupling to achieve a biochemical function is necessary in a variety of physiological and pharmacological milieus [5]. RXRs as paralogues are ubiquitously expressed including in the central nervous system (CNS) and peripheral nervous system (PNS) although specific isotypes display more restricted expression patterns [3,7].

Through their ligand-activated heterodimeric complexes, RXRs regulate transcription of genes that play critical role in cellular differentiation and metabolic processes including lipid and glucose metabolism in neurons $[2,3,8]$. RXR ligands such as bexarotene or honokiol have been extensively studied and demonstrated to exhibit neuroprotective effects in animal models of glaucoma, Alzheimer disease (AD), and Parkinson disease (PD) [9-12]. The receptors are also implicated in microglial activation to protect tissues against neuroinflammatory response and mediate clearance of debris in multiple sclerosis (MS) and brain stroke pathology although involvement of specific homo- or heterodimers with other partners need to be further investigated [13, 14]. This diverse RXR functional spectrum is attributed to the fact that RXRs are positioned centrally in the nuclear receptor signalling network interacting directly and indirectly with transcriptional machinery frequently in a ligand-dependent manner [3]. As our understanding of RXRs and their heterodimers in regulating transcription, homeostasis, neuronal differentiation, neuroinflammation, and neuroprotective effects has expanded in recent years, RXRs have emerged as a promising therapeutic target in neurological disorders. This review discusses our current understanding of the structure, ligands, interactions, and functions of RXR. We also discuss the involvement of RXRs in various neuronal disorders and the potential therapeutic prospects of modulating the receptor function. The review closes with a brief discussion of on-going clinical trials and provides future perspectives of RXR and its partners in neurological research.

\section{Historical Importance and Positioning of RXR in Nuclear Receptor Superfamily}

In 1990, the molecular cloning and transcriptional activation studies performed by Mangelsdorf and co-workers identified RXR that responded specifically to the vitamin 
A metabolites [15]. RXR differed in structure from the previously identified transcriptional regulator retinoic acid receptor (RAR) [15] but had an analogous mechanism of transcriptional regulation with that of steroid and thyroid hormone receptors (THR) [15]. Further characterisation of RXR and its activation by 9-cis retinoic acid (9-cis-RA) but not all-trans RA, the latter being an endogenous ligand of RARs, resulted in recognition of a new retinoid response pathway that not only differed from RAR in response to retinoids but was also evolutionarily conserved [15] and demonstrated ability to heterodimerise with multiple receptors [5, 6]. Due to this reason, RXR was established as one of the founding members of the "adopted" orphan class of nuclear receptors [5]. Mangelsdorf and co-workers (2014) called the discovery of the ligand activation mechanism of the RXR and its ability to heterodimerise with other nuclear receptors as a "big bang" discovery [5]. Although 9-cis-RA was referenced for a long time as potential physiological, endogenous ligand of RXRs, its detection in physiological conditions was questionable leading in 2015 to the identification of 9-cis-13,14-dihydroretinoic acid (9-cis-DHRA) as the first endogenous retinoid acting as RXR agonist [16]. Various dietary lipid metabolites such as fatty acids, bile acids, and xenobiotic lipids have also been characterised as ligands for RXR-partnered orphan receptors [17, 18].

Currently, the nuclear receptor superfamily is comprised of 48 members in humans although this number may vary across different species, for example, teleost zebrafish has been reported to have 73 nuclear receptor members $[2,19$, 20]. In metazoan physiology, nuclear receptors modulate gene expression in response to small lipid-based molecules such as natural hormones, lipids, bile acids, or synthetic ligands [21]. Ligand binding induces conformational changes in the receptor and stimulates a cascade of downstream events that direct the nuclear receptor to the DNA transcriptional regulation sites [22]. The nuclear receptors are divided into four types based on the mechanisms in which nuclear receptors bind to their respective ligands, attributing RXR the highest promiscuity amongst nuclear receptor superfamily. A detailed review by Evans and coworkers (2014) described binding ability of RXR's permissive and non-permissive partners and their corresponding pleiotropic functional roles [5]. RXR forms heterodimers or tetramers with the ligand-activated partners and plays crucial roles in regulating cellular pathophysiology [5].

\section{Molecular Structure of the RXR}

Similar to the other nuclear receptors, human RXR (Uniprot no. P19793) protein structure consists of multiple functional domains [17]. These domains include a poorly conserved and variable length $\mathrm{N}$-terminal domain (NTD) (domain A/B) [3, 5] (Fig. 1A) which includes a ligandindependent activation coactivator binding region AF1 $[3,17]$. There is also a highly conserved DNA-binding domain (DBD) that contains two zinc-finger motifs (domain $\mathrm{C}$ ), which mediate RXR binding to specific DNA sequences [3, 17]. A flexible hinge (domain D) connects the DNA and ligand binding domain (LBD) (domain E) [3, 17] (Fig. 1A). LBD is highly conserved and contains activation function (AF-2) sequence to which the coactivators (CoAs) or corepressors (CoRs) bind to regulate the transcription activation [3, 17] (Fig. 1B, C). The DBD comprises of two zinc-finger domains that bind and interact with the phosphate backbone and nucleotides of the DNA major groove facilitating DNA dimerisation [23]. The hinge area next to the DBD constitutes of approximately 201-229 residues in human RXRs. This area provides flexibility to the RXR-LBD region so that it accommodates LBD motif from other nuclear receptors such as from PPAR. RXR crystallographic studies have further elucidated the molecular basis of heterodimeric interactions of RXR [22, 24-26]. The biophysical nature of RXR and its heterodimers was also discussed by Nagy and coworkers (2004) [27]. Essential for such interactions is the ligand binding domain which activates the bound receptors into potent activators of transcription [3,28].

To understand the heterodimerisation ability of RXR and its transactivation of target genes, we need to understand the DNA sequence-specificity for RXR binding [29]. Classical regulatory elements recognised by RXR heterodimers consist of two direct repeat (DR) half sites separated by 2, 3, 4, or more nucleotides (e.g. 5'-AGG TCA-N $\mathrm{N}_{\mathrm{x}}$-AGGTCA-3') to form DR2, DR3, or DR4 binding sites, whereas in homodimerisation process, RXR binds to DRs separated by one nucleotide called DR1 [23, 30]. DR1 requires the sequential introduction of single nucleotides within the spacer of two DR1 half sites, in turn, generating novel binding motifs such as DR2, DR3, DR4, and so on. [30]. This flexibility due to the innate structure of the RXR-LBD allows it to adopt various conformations that lead to its heterodimerisation ability with PPAR, LXR, FXR, PXR, and CAR receptors [30]. In the case of the RXR/PPAR, the heterodimer preferentially binds to PPAR response element, which consists of two half sites separated by single nucleotide [23]. Due to this molecular plasticity, each heterodimer can occupy one of the half sites, while RXR continues to bind to the remaining moiety [5]. This DR1 sequence was suggested as an important determinant that has likely played a role in molecular evolution of RXRs [5]. It grants RXR flexibility in its ligand binding ability with multiple partners as the interactions are not hardwired and are dependent on the DNA-binding sites that can undergo induced fit adjustment to allow the dimerisation process $[5,31]$. 


\section{[A]}

\begin{tabular}{ccccc} 
A/B (NTD) & C & D & E \\
& DNA-Binding Domain & Hinge & Ligand Binding Domain (LBD) \\
$\begin{array}{c}\text { Variable size/ } \\
\text { sequence } \\
\text { AF-1 function }\end{array}$ & Highly conserved & $\begin{array}{c}\text { Variable size/ } \\
\text { sequence }\end{array}$ & 12 helical fold \\
\hline
\end{tabular}

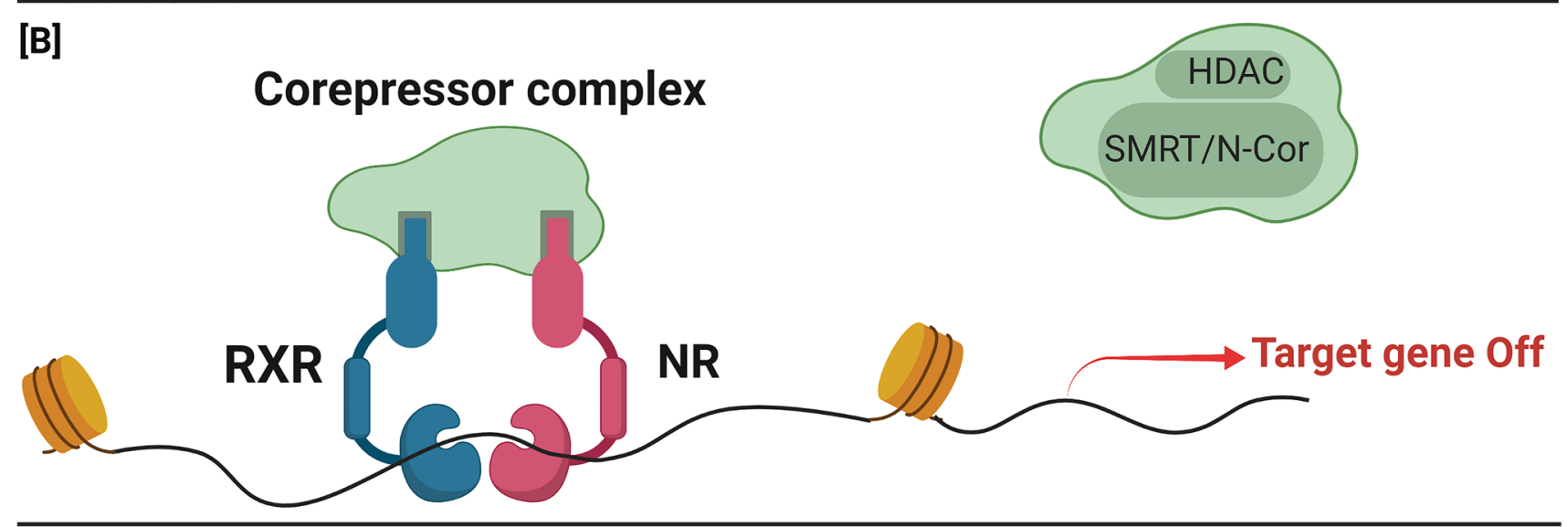

[C]

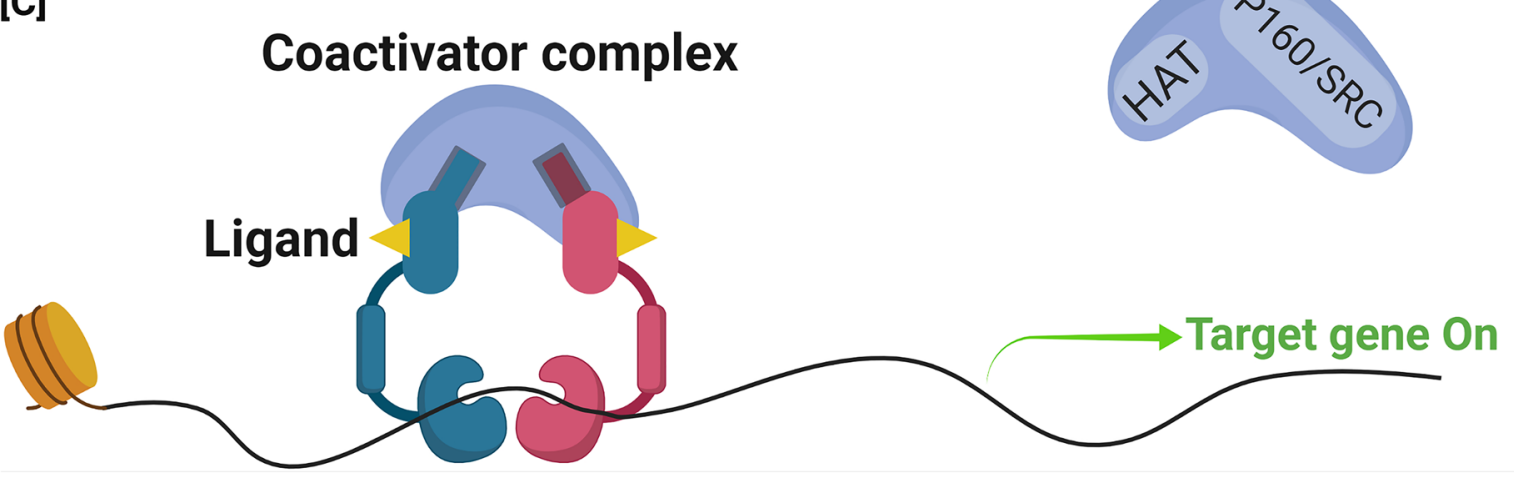

Fig. 1 Structure of RXR and its transactivation, A Schematic representation showing six functional domains of RXR, which include $\mathrm{N}$-terminal activation function 1 (AF1), DNA-binding, ligand-binding, and C-terminal AF2 domains. RXR heterodimers binds with the response element of the promoter region of the target gene. B In the absence of agonist ligand, AF-2 domain promotes interaction with corepressor complex [histone deacetylase (HDAC) and silencing mediator for retinoid and thyroid receptors/nuclear receptor corepressor (SMRT/N-Cor)] which blocks the transcription process. C Ligand interaction may cause conformational changes in the AF2 domain, which destabilises corepressor interaction and promotes coactivator [histone acetyltransferases (HAT) and p160/steroid receptor coactivator (P160/SRC)] binding leading to activation of target gene transcription process

\section{RXR Isotypes and Their Expression}

In mammals, $\mathrm{RXR}$ exists in three isotypes, $\mathrm{RXR} \alpha, \beta$, and $\gamma$, also known as NR2B1, 2, and 3 encoded by distinct genes $(9 \mathrm{q} 34.2,6 \mathrm{p} 21.32,1 \mathrm{q} 23.3$ in human) and on mouse chromosomes 2,17 , and 1 , respectively $[15,32]$. Human $\operatorname{RXR} \alpha, \beta$, and $\gamma$ share $97.4 \%, 94.75 \%$, and $98.27 \%$ homology, respectively, with their mouse counterparts in their ligand binding domain sequence (225-462) [32].

\section{RXRa}

This protein belongs to nuclear receptor subfamily 2 group $\mathrm{B}$ member 1 and human RXR $\alpha$ comprises of an open reading frame of 462 amino acids with molecular mass $50,811 \mathrm{Da}$ [15]. It has been identified to be localised in the nucleus, cytoplasm, and mitochondria [32]. RXR $\alpha$ is a predominant isotype expressed in liver, kidney, and brain tissues. Alternate splicing may lead to further heterogeneity by generating different 
isotypes: $\mathrm{RXR} \alpha 1, \alpha 2, \alpha 3$, and $\alpha 4$ [33]. RXR $\alpha 1$ is the major isotype expressed in most tissues, while RXR $\alpha 2$ and $R X R \alpha 3$ have been identified in the testis and RXR $\alpha 4$ in not yet characterised functionally [33].

\section{RXR $\beta$}

Human RXR $\beta$ is localised on chromosome $6 \mathrm{p} 21.32$ proximal to HLA class II gene [34]. It is specifically expressed in the endothelial cells and monocytes and has been detected in multiple cancer cell lines [32]. The human homologue of mouse $\beta 1$ isoform, RXR $\beta 2$, is largely conserved across species with two ATG initiator codons that could produce $\mathrm{N}$-terminal variants [35]. The third isoform mouse RXR $\beta 2$ E contains an SLSR (a four amino acid sequence) in the ligand binding domain that was shown to negatively impact transactivation process [36]. In the mouse CNS, RXR $\beta$ is semi-ubiquitously expressed with different contribution of different isoforms depending on brain region $[7,37]$.

\section{RXRY}

This gene is $14 \mathrm{~kb}$ long comprising nine introns with size ranging from 107 base pairs to more than $30 \mathrm{~kb}$. $\operatorname{mRXR} \gamma 1$ gene product is encoded by 10 exons, while $\operatorname{mRXR} \gamma 2$ is transcribed from and alternative promoted on the 3rd exon $[32,38]$. mRXR $\gamma 1$ is highly expressed in muscle and brain tissues, while $\operatorname{mRXR} \gamma 2$ is expressed predominantly in the skeletal and cardiac muscle [38]. Expression of RXR $\gamma$ in mouse brain is very high but restricted only to few brain regions including the striatum, dispersed cells within frontal and entorhinal cortex, hippocampus, and amygdala [7, 39]. Further, $\mathrm{RXR} \gamma^{-1-}$ knockout BALBcByJ mice display memory deficits and depression-like behaviour [40].

The fine-tuning of RXR transcriptional activity is also affected by post-translational modifications (PTMs) [41]. The phosphorylation of human RXR $\alpha$ at Ser 260 via activated Ras-Raf-MAPK cascade modulates CoA recruitment to the RXR/VDR heterodimers [41]. RXR phosphorylation on distinct Ser residues regulates its cooperation with RAR, and this PTM has been demonstrated to be relevant for both the transcription of the retinoic acid target genes and degradation of the receptors [42]. These specific effects of particular PTMs on RXR activity underscore the flexibility of receptor structure-function relationship and emphasises PTM roles in regulating RXR signalling [41]. However, the epigenetic landscape of RXR and its interactions continues to be understudied.

\section{Understanding RXR Evolutionary Conservation in Context of Ligand Binding Function}

RXR have been recognised across most metazoan species, with the earliest RXR orthologue documented in Trichoplax adhaerens (Ta) [43, 44]. Similar to the case with nuclear receptors in general, RXRs have not been identified in fungi, plants, or unicellular eukaryotes [45]. Ta RXR shares $81 \%$ of homology with DBD and $70 \%$ with LBD of the human RXR. The DNA-binding motif specificity is conserved up to $85 \%$ with that of human RXR $\alpha$ [46].

More recently, 9-cis-DHRA, an endogenous physiological RXR ligand, identified in 2015, has been suggested to be a prototype ancestral retinoid that evolved to be a RXR ligand in vertebrates $[16,47,48]$. Importantly, this ligand is an active form of vitamin A5/X, a new class of vitamin A comprising 9-cis-13,14-dihydroretinol and 9-cis-13,14dihydro- $\beta, \beta$-carotene as nutritional precursors which are distinct from those known for classical vitamin A1 pathway defined by all-trans $\beta, \beta$-carotene, and all-trans retinoids [39]. Understanding the metabolism of 9-cis-DHRA and its precursors in different species together with their nutritional availability in species-respective environments will help trace the relevance of this intriguing ligand and help understand the genetic and environmental interplay in shaping the ligand-receptor interactions of RXR [49].

\section{RXR Interacting Partners and Ligands}

A very high evolutionary conservation of RXR-LBD has resulted in identical ligand binding pocket structure amongst all three RXR paralogs in human and mouse. This suggests similar ligand specificity and possibly overlapping protein interaction partners amongst different isotypes [3]. The involvement of LBD, both in ligand binding and interactions with other receptors and coregulators, not only allows multiple partners for RXR but also serves as a perfect model to understand the receptor structure-activity relationship [48]. Deciphering the dynamics of RXR with its interacting partners will facilitate understanding of their biochemical and signalling roles. The list of RXR protein partners includes (i) transcription factors, (ii) transcriptional cofactors including CoAs and CoRs, (iii) DNA-modifying agents and, and (iv) other proteins in its subcellular vicinity [3]. RXR interactions with multiple protein partners underlie pleiotropic effects in multiple biological processes, but the true extent and significance of these interactions in various physiological and disease conditions remain to be elucidated [3]. Importantly, RXR 
ligands may differentially affect activities of different RXR heterodimers [45]. This section will discuss both endogenous ligands of RXR and exogenous ligands reported from natural sources or prepared synthetically.

\section{Endogenous Ligands}

Naturally occurring ligands, such as endogenous or nutritional, bind to RXRs and may serve as molecular regulator of various physiological functions [50]. The search for an endogenous ligand for RXR has been technically challenging. For a long time, 9-cis-RA was suggested as an endogenously occurring functionally relevant RXR ligand; however, a number of studies reported that in physiological conditions, 9-cis-RA was either not detected or was present at concentrations insufficient to bind and activate RXRmediated signalling [16]. Accordingly, 9-cis-RA has been detected in the range of 0.03 to $0.003 \mathrm{nM}$ in various tissues $[47,51]$; however the minimal concentration required for transactivation of RXR is $10-100 \mathrm{nM}[16,52]$. Therefore, such low levels may not be sufficient to induce RXR transactivation in vivo, minimising the likelihood of 9-cis-RA acting as endogenous physiological ligand for RXR [47, 53, 54].

Using LC-MS/MS and dedicated standards, Rühl and co-workers (2015) identified the presence of 9-cis-DHRA in mouse liver $(\sim 450 \mathrm{nM})$, serum $(\sim 400 \mathrm{nM})$, and brain $(\sim 130 \mathrm{nM})$ tissues with concentrations sufficient to induce and maintain RXR-dependent activities [16, 48]. Crystallographic studies established that 9-cis-DHRA binds to the RXR $\alpha$-LBD in a mechanism similar to that reported for 9-cis-RA and triggers RXR transactivation at about $100 \mathrm{nM}$ levels [16]. In monocyte-derived human dendritic cells, 9-cis-DHRA also transactivated target genes in the heterodimer complexes LXR/RXR, PPAR/RXR, and RAR/ RXR [16]. Reduced levels of 9-cis-DHRA were observed in $\mathrm{Rbp}^{-/-}$(cellular retinol binding protein) mice brains, liver, and plasma reflecting on the compromised RXR-mediated signalling in the absence of this protein, leading to memory deficits [16]. Further studies may unravel the biochemical roles and pathophysiological relevance of the 9-cis-DHRA in the CNS. Thus, 9-cis-RA and endogenous 9-cis-DHRA may be relevant for the activation of permissive RXR heterodimers including also RAR/RXR heterodimers as both retinoids can bind and transactivate RARs in nanomolar range [55].

Fatty acids constitute an important category of RXR ligands. A series of the free fatty acids (FFAs) including in particular docosahexaenoic acid (DHA) or eicosapentaenoic acid (EPA) can bind RXRs with varying affinities and induce their transcriptional activation at different concentrations [56]. The efficiency of DHA in transactivation of RXR influencing neuronal function was best shown at $10 \mu \mathrm{M}$ concentration compared to other FFAs like docosatetraenoic, oleic, and arachidonic acids that may activate RXR at 50-100 $\mu \mathrm{M}$ concentrations [56]. DHA can activate RXR $\alpha$ and induce neurite outgrowth in neuronal cells at low concentration [57]. Arachidonic acid is also shown to activate the RXR $\alpha$ isoform but with lower efficacy [57]. Accordingly, DHA in retina was shown to promote survival of rat photoreceptors upon $\mathrm{H}_{2} \mathrm{O}_{2}$ or paraquat-induced oxidative stress through activation of RXRs and the ERK/MAPK signalling pathway [58]. Another branched chain FFA, phytanic acid, demonstrated binding and activation of RXR $\alpha$ similarly to 9-cis-RA in rodents [59] but failed to induce RXR activation in human cell lines [60]. Phytanic acid concentration greater by three order of magnitude compared to that of 9-cis-RA was required to elicit similar effects [61]. Requirement of high concentrations of these diverse fatty acids or their metabolites for activation of RXR-mediated signalling makes them good candidates for direct or indirect nutritional ligands of RXRs, relevant for modulating RXR activities after nutritionally induced rise in their concentration but might be less relevant for physiological due to insufficient concentrations [48].

\section{Exogenous Ligands}

Naturally Occurring Ligands Several bioactive compounds isolated from traditional medicinal plant sources have been identified as RXR ligands. The first of such natural compound identified was honokiol, which was isolated from genus Magnolia and has been extensively studied in its relevance to the neurological disorders [62]. Honokiol activates the apolipoprotein E (ApoE)/ATP binding cassette transporter1 (ABCA1) expression through RXR-dependent mechanism [62]. The compound was shown to regulate cholesterol metabolism and homoeostasis by direct activation of the LXR/RXR $\beta$ in murine astrocytes and in neuronal culture at $\mathrm{EC}_{50} \sim 10 \mu \mathrm{M}$ [62]. In addition to its roles in lipid metabolism, honokiol also regulates glucose uptake by cells and activates the PPAR $\gamma /$ RXR signalling by directly binding to the PPAR $\gamma$ [63]. Honokiol has also shown neuroprotective and anti-neuroinflammatory effects in $\mathrm{AD}$ and $\mathrm{PD}$, but whether this activity is mediated via RXR activation remains to be established $[64,65]$. Another ligand, magnolol, also isolated from Magnolia officinalis, has been shown to interact with RXR $\alpha$ and PPAR $\gamma$ with $\mathrm{EC}_{50} \sim 40 \mu \mathrm{M}$ and $\sim 2 \mu \mathrm{M}$, respectively, showing its preference for activation of PPAR $\gamma /$ RXR heterodimers at $\mathrm{EC}_{50} \sim 10 \mu \mathrm{M}[66]$.

There are a few more naturally identified ligands of RXR such as drupanin, isolated from Brazilian green propolis with selective affinity towards PPAR $\gamma / \mathrm{RXR}$ heterodimer and capable of performing transactivation at $\mathrm{EC}_{50}$ of 2-7 $\mu \mathrm{M}$ [67]. Flavanones isolated from Sophora tonkinensis 
also showed specific agnostic activity for RXR and activated direct target genes of RXR/LXR, RXR/PPAR $\beta / \delta$, and PPAR $\gamma$ complexes [68]. Bigelovin, a sesquiterpene lactone isolated Inula hupehensis, binds specifically to RXR $\alpha$-LBD with demonstrated anti-carcinogenic properties as observed in colon cancer cells [69]. Crystallographic evidence has shown that RXR-LBD binding mechanism with bigelovin is remarkably distinct from that observed with other RXR ligands [69]. This might explain limited capability of the ligand to activate FXR/RXR $\alpha$ heterodimer complex while inducing transactivation of other heterodimeric complexes [66]. More recently, valerenic acid, a sesquiterpenoid, isolated from Valeriana officinalis has been shown to bind and activate RXR [70]. Valerenic acid is a highly specific ligand of RXR with no affinity towards PPAR, LXR, RAR, FXR, VDR, PXR, and CAR receptors [70]. Valerenic acid binding to RXR was shown to efficiently transactivate RXR target genes ABCA1 and $\mathrm{ApoE}$ at $\mathrm{EC}_{50}=5 \mu \mathrm{M}$ for $\mathrm{RXR} \beta$, $\mathrm{EC}_{50}=27 \mu \mathrm{M}$ for $\mathrm{RXR} \alpha$, and $\mathrm{EC}_{50}=43 \mu \mathrm{M}$ for RXR $\gamma$ isoforms [70]. Further pharmacokinetic and pharmacodynamic studies will establish the therapeutic potential of these naturally occurring RXR ligands in various health and disease processes.

Synthetic Ligands Several structural mimetics of the naturally occurring RXR ligands have been identified that interact with RXR-LBD domain and regulate its activity. Here, we discuss some of the potent synthetic ligands that have been shown to interact with RXR and exert neurological effects. Bexarotene (LGD1069) is a pan-RXR agonist and an approved US-FDA anticancer treatment for cutaneous $\mathrm{T}$ cell lymphoma [71]. The drug selectively binds to $\operatorname{RXR} \alpha, \beta$, and $\gamma$ isotypes with high affinity as demonstrated by $K_{\mathrm{d}}$ values of $14 \pm 3 \mathrm{nM} ; 21 \pm 4 \mathrm{nM}$; and $29 \pm 7 \mathrm{nM}$, respectively, in comparison to RAR $\left(K_{\mathrm{d}}>1000 \mathrm{nM}\right)$ [72]. Chitranshi and coworkers (2019) reported on binding affinity of RXR agonists to RXR using molecular docking and computational simulation techniques [73]. Dynamic simulation studies confirmed that the hydrogen bonding and hydrophobic interactions were highly stable in all the three isoforms of the RXR-bexarotene complex showing Ala and Arg (Ala327 and Arg316 in RXR $\alpha$; $\operatorname{Arg} 387$ and Ala398 in RXR $\beta$; and Arg95 and Ala106 in $\operatorname{RXR} \gamma$ ) as key interacting residues when compared to other RXR agonists such as RA, calcitriol, tamibarotene, and acitretin [73]. Bexarotene showed high binding with the RXR $\alpha$ and $\beta$ compared to the RA, while $\operatorname{RXR} \gamma$ LBD displayed weaker affinity [73]. Biological assays demonstrated that RXR-bexarotene interactions promote neurite growth in SH-SY5Y neuronal cells [73]. Importantly, this study suggested that RXR $\gamma$-bexarotene complex is rather unstable in comparison to the RXR $\alpha / \beta$ complex formation, supporting that further pharmacodynamic investigations are required to understand the differential effects of bexarotene on RXR isotypes in neurodegenerative disorders [73]. In the PD murine model, bexarotene mediated activation of Nurr1/RXR heterodimer complex imparting neuroprotective effects and restored behavioural functions [8]. Recently, our group demonstrated the ability of bexarotene to induce RXR activation in the neuronal cells and retinal tissues [9, 10]. Bexarotene treatment $(0.1 \mu \mathrm{M})$ protected the neuronal cells against $\mathrm{A} \beta$-induced endoplasmic reticulum (ER) stress and suppressed pro-apoptotic BAD protein activation while promoting neurite outgrowth [10]. At higher concentrations, bexarotene $(10 \mu \mathrm{M})$ showed an upregulation of neurotoxic effects which was prevented by inducing pharmacological activation of the tropomyosin receptor kinase B (TrkB) receptor signalling $[9,10]$. In another study, bexarotene reduced the levels of soluble $A \beta$ in the brain interstitial fluid by $25 \%$ in 2-month-old APP/PS1 mice via RXR activation [74]. The administration of bexarotene has been shown to enhance clearance of soluble $A \beta$ from the brain within hours in an ApoE-dependent manner in a mouse model of $\mathrm{AD}$, providing a rationale to develop this anticancer drug as a potential AD therapeutic agent [75]. Bexarotene-activated RXR also induces expression of oestrogen-synthesising enzymes in hippocampal slice cultures [76]. The structural analogue of bexarotene, LG100268, was found to exhibit much higher affinity for RXR with Kd of $3 \mathrm{nM}$. LG100268 caused transactivation of RXR at concentration that is at least tenfold lower than that of 9-cis-RA [72]. Treatment with this drug was also observed to induce several target genes during monocyte differentiation into dendritic cells or during osteoclast differentiation by activation of RXR homodimers as indicated by transcriptome profiling [77]. The compound was also demonstrated to activate LXR/ RXR, and the PPAR $\gamma /$ RXR heterodimers and downstream consequences of their actions need to be studied for better understanding of its mode-of-mechanism [78].

Other ligands with varying levels of interaction affinity and impact on RXR conformation such as CBt-PMN have been reported [79]. This pharmacophore selectively binds and activates heterodimers of LXR $\alpha / \mathrm{RXR} \alpha$ and PPAR $\gamma /$ $\mathrm{RXR} \alpha$ in vitro $\left(\mathrm{EC}_{50}=143 \mathrm{nM}\right)$ and in vivo $\left(\mathrm{EC}_{50}=15 \mathrm{nM}\right)$ [79]. RXR activation using CBt-PMN was implicated in providing beneficial effects in mediating glucose regulation in animal models of type 2 diabetes [79]. Further, chemical library screening experiments revealed that XCT0135908 was able to selectively activate the Nurr1/RXR heterodimers which could find applications in the preservation of nigrostriatal dopamine system in PD [80]. Similar effects have been reported for other selective activator of Nurr1/ RXR, such as HX600 [81]. In addition, inhibitors of sterol biosynthesis, such as pitavastatin, fluvastatin, and their analogues, demonstrate varying levels of RXR $\alpha$ antagonism [82]. Rosiglitazone and domperidone were shown to exhibit 
RXR agonistic action in the presence of 9-cis-RA, wherein these compounds activated PPAR/RXR heterodimer complex and modulated glucose metabolism [82]. Furthermore, treatment with methoprene acid (MPA) which is a pesticide was shown to induce transcription at RXR-specific CRBPII promoter for all three RXR isotypes with $\mathrm{EC}_{50}$ of $2 \mu \mathrm{M}$ in insect and $20 \mu \mathrm{M}$ in mammalian cell lines, respectively [83]. Its parent molecule, methoprene, also induced upregulation of the target genes ABCA1 and ABCG1 implicated in regulating cholesterol efflux in rat astrocytes [83]. Altogether, these endogenous and exogenous ligands of RXR exhibit a range of biochemical effects and modulate various metabolic processes under both physiological and disease conditions.

\section{RXR Involvement in Various Biochemical Networks}

RXRs are crucial regulators of macrophage lipid metabolism, monocyte migration, ApoE synthesis, and cholesterol homeostasis in astrocytes, regulating inflammatory responses of microglia and oligodendrocyte progenitor cell differentiation [4, 84-87]. This involvement of RXR in multiple biochemical networks is concomitant with its ubiquitous expression in tissues such as the liver, kidneys, small intestine, cardiac myocytes, monocytes, macrophages, Kupffer cells, adipose tissue, and colon mucosa [88-94]. This section will elucidate the roles of the RXR and its heterodimers in various biochemical and metabolic networks.

\section{Role of RXR and Its Partners in Reducing Cellular Stress and Neuroinflammation}

RXR heterodimerises with its permissive partners modulate unfolded protein response (UPR) and other ER stress pathways [95]. Treatment with RXR agonist bexarotene was shown to reduce the expression of p-PERK and GADD153 ER markers in SH-SY5Y cells treated with neurotoxic $\beta$-amyloid $(\mathrm{A} \beta)$ in a dose-dependent manner [10]. Treatment with low concentrations of bexarotene also alleviated the expression of pro-apoptotic BAD proteins in AD mouse model [10] (Fig. 2 (1)). In another study conducted by our group, treatment with bexarotene protected retinal ganglion cells in glaucoma mouse models that were associated with reduction in expression of ER stress markers [9]. The ligandactivated PPAR $\gamma /$ RXR has previously been demonstrated to alleviate mitochondrial stress response accompanied by upregulation of UCP2, eNOS, and MnSOD scavenger proteins and reduced $\mathrm{O}_{2}^{-}$radical accumulation in the mitochondria [96, 97] (Fig. 2 (2)). Nurr1 is highly expressed in the CNS forming heterodimers with RXRs, and its activation is associated with RXR ligand LG268-induced neuroprotection in ventral midbrain cultures [80]. Nurr1 transcription complex activation is involved in midbrain dopaminergic (DA) and serotonergic neurogenesis along with activation of PITX3 and Wnt/ $\beta$-catenin signalling $[98,99]$. Separately, $\mathrm{RXR} \alpha$ also inhibits the transcription of $\beta$-catenin and directly regulates the $\mathrm{Wnt} / \beta$-catenin cascade in colon cancer cells suggesting $\operatorname{RXR} \alpha-\beta$-catenin axis as a potential therapeutic target [94] (Fig. 2 (3)). Dickey and co-workers (2017) demonstrated that bexarotene may reverse impaired oxidative metabolism and rescue altered mitochondrial morphology in neuronal cells derived from N171-82Q Huntington disease mouse model [100]. The agonist treatment resulted in improved proteostasis by inducing autophagy via its effects on PPAR $\delta$ activation and controlling overall cellular quality control to achieve neuroprotection [100].

RXR heterodimerisation with PPAR, LXR, and Nurr1 also plays a role in regulating adaptive immune response and macrophage, monocyte, dendritic cell, and $\mathrm{T}$ cell functions through clearance of dead cells, $\mathrm{T}$ cell differentiation, and regulating gene repression of inflammatory mediators [101, 102]. Nurr1 was demonstrated to inhibit pro-inflammatory genes in LPS treated astrocytic and microglial cultures through NF-кB modulation [103] (Fig. 2 (4)). RXR $\alpha$ independently and in RXR/PPAR $\delta$ complex influences innate inflammatory response by modulatory effects on cytokine and chemokine expression in myeloid cells and monocytes/ macrophages [104, 105] (Fig. 2 (5)). Similar inhibition of the pro-inflammatory cytokines achieved through activation of LXR/RXR, PPAR $\alpha / R X R \alpha$, and STAT3 pathways in inflammation-induced corneal angiogenesis has been reported to impart protection against inflammatory changes in rat cornea [106]. Baicalein (5,6,7-trihydroxyflavone), a flavonoid, was shown to enhance the PPAR $\delta$ expression in brain microglia and suppress MAPK and NF- $\mathrm{KB}$ signalling resulting in augmentation of anti-inflammatory effects [107]. Similar attenuation of the neuroinflammation mediated by bexarotene has been implicated in rat model of subarachnoid haemorrhage [108]. These anti-inflammatory actions were shown to be mediated through its regulatory effects on PPAR $\gamma$, SIRT6, and FoxO3A [108]. In addition, PPAR $\gamma$-coactivator- $1 \alpha$ (PGC- $1 \alpha)$ which is a co-factor for transcription was implicated in the amelioration of microglial activation and reduced expression of amyloid precursor protein cleaving enzyme (BACE1) in APP23 AD mouse model [109, 110] (Fig. 2 (6)). RXR-activated PPAR $\gamma$ regulates oxidative stress response and prevents autophagy in association with increased expression of NRF2 in vivo in status epilepticus (SE) [111]. It was shown that PPAR $\gamma / R X R$ complex upon binding to its agonist rosiglitazone provided significant protection against hippocampal neuronal loss in epileptic rat model, attributed to enhanced expression of antioxidant GSH [111, 112] (Fig. 2 (7)). The overexpression of the PPAR $\gamma$ also led to increased expression of anti-apoptotic protein $\mathrm{Bcl}-2$, leading to mitochondrial stabilisation in 


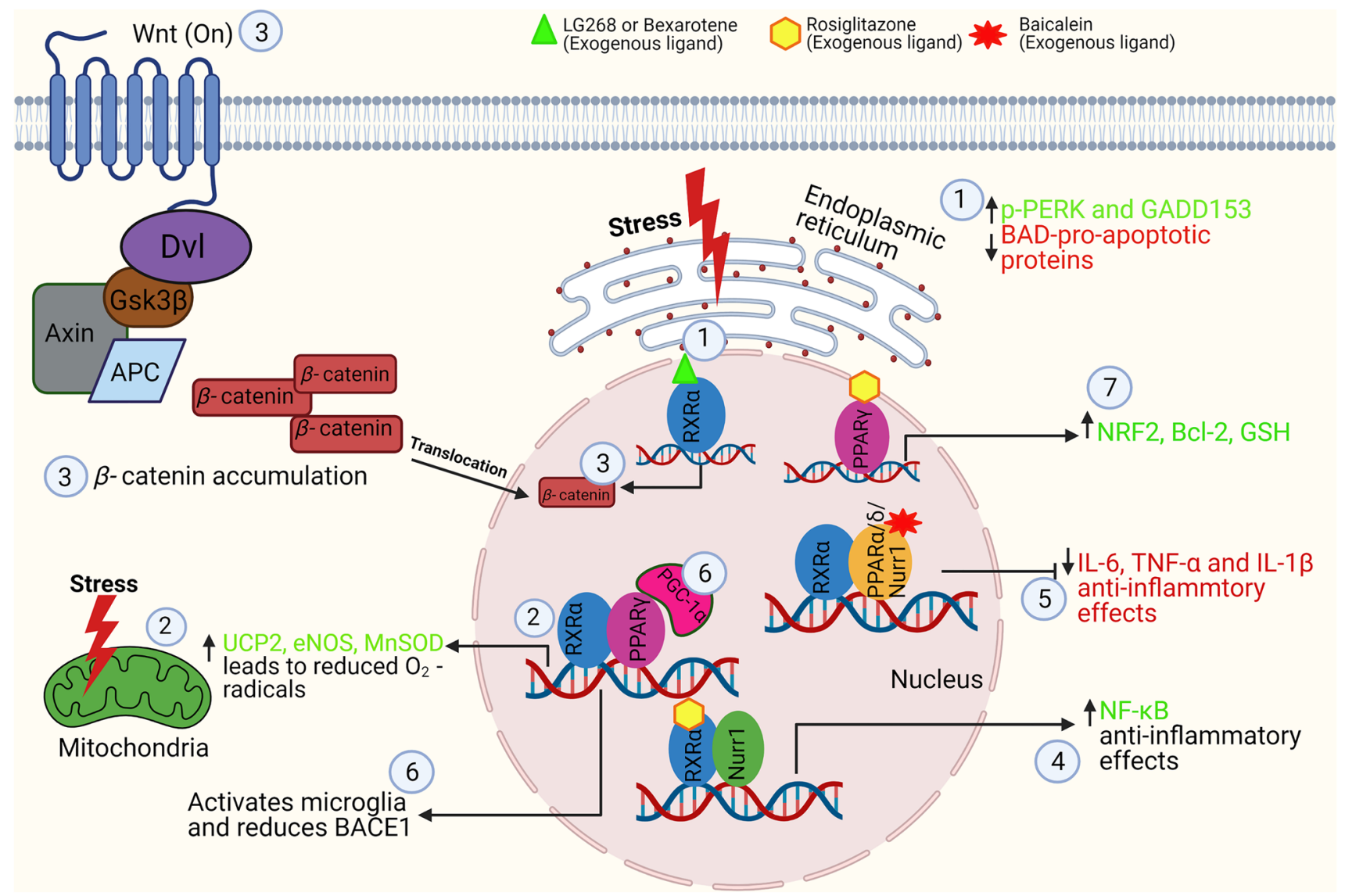

Fig. 2 Schematic representation of RXR and its partners in reducing neuronal stress and neuroinflammatory effects: RXR stimulation by exogenous ligand bexarotene reduces the endoplasmic reticulum stress markers p-PERK and GADD153 in retinal ganglion cells and supresses BAD protein activation (1). Activation of the RXR $\alpha /$ PPAR $\gamma$ heterodimer with ligands activates proteins UCP2, eNOS, and MnSOD to reduce mitochondrial stress (2). The RXR $\alpha$ heterodimer regulates transcription of $\beta$-catenin (3). LG268 and bexarotene binds to RXR $\alpha / \mathrm{PPAR} \alpha / \beta$ and Nurr1 forming a heterodimer complex that inhibits TNF- $\alpha$, IL-1 $\beta$, and IL6 and promotes NF- $\kappa B$ antiinflammatory effects in microglia and macrophages $(4,5)$. A PPAR $\gamma$ coactivator- $1 \alpha$ (PGC-1 $\alpha)$ reduces expression of BACE-1, a $\beta$-amyloid $(\mathrm{A} \beta)$ precursor protein cleaving enzyme (6). PPAR $\gamma$ increases the expression antioxidants $\mathrm{GSH}, \mathrm{NRF} 2$, and $\mathrm{Bcl}-2$ to play a protective role against apoptosis (7)

by agonists such as 9-cis-RA, bexarotene, LG100268, or honokiol, RXR/PPAR $\gamma / \mathrm{LXR}$ has been implicated in directly regulating cholesterol efflux by mediating transcription of ABCA1 and ABCG1 [62, 63, 117] (Fig. 3B). PPAR $\gamma$ activation is associated with immune-phenotype manifestations of monocyte-derived dendritic cells through its regulatory effects on genes involved in lipid metabolism, storage, and transport [118]. Moreover, in macrophages, scavenger receptor class B member 3 (SRB1) and the scavenger class A (SRA) proteins are important receptors for the uptake of various lipid molecules, and their impairment could contribute to atherosclerosis pathology $[119,120]$ (Fig. 3B). ABCA1 dysfunction in the brain is associated with reduced levels of ApoE [121, 122]. The cholesterol transcytosis between neurons and astrocytes mediated by ApoE, ABCA1, and ABCG1 occurs in an LXR-dependent manner [123]. Cholesterol being one of major components of the myelin sheath GBM [116]. In monocytes and macrophages, stimulated 


\section{A.}
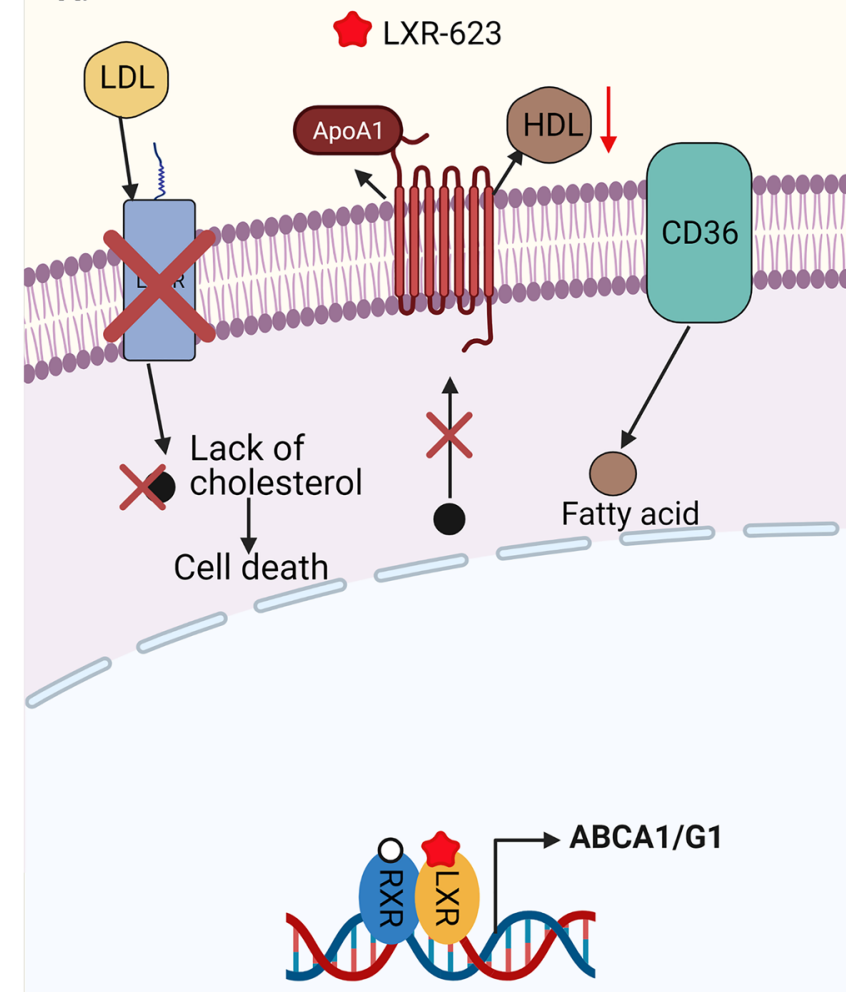

B.

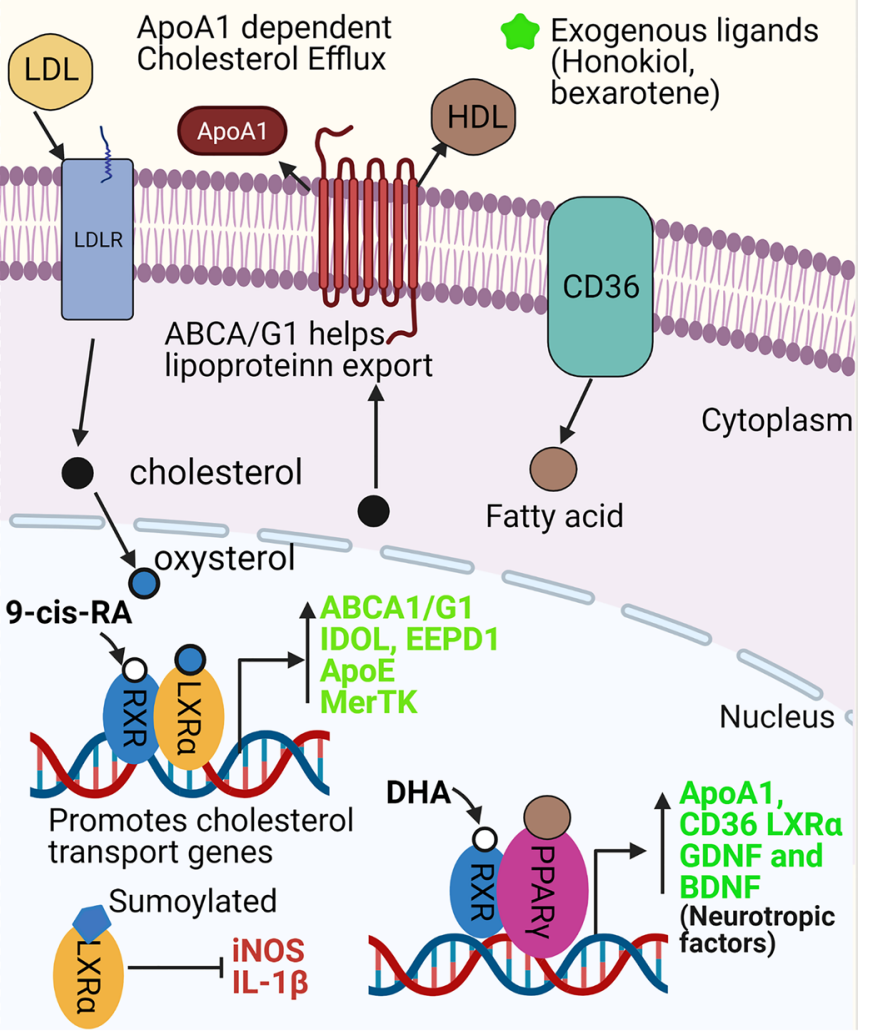

heterodimerise to induce the transcription of ATP binding cassette transporter (ABCA1/G1) which is responsible for the efflux of cholesterol from the cell. RXR/LXR $\alpha$ complex induces transcription of inducible degrader of the LDLR (IDOL), ApoE, MerTK, and EEPD1. Cholesterol is imported into the cell through low-density lipoprotein receptors (LDLRs), and fatty acid is imported by CD36. Exogenous ligands honokiol or bexarotene activate RXR in the RXR/ PPAR $\gamma$ complex. Further, PPAR $\gamma / \alpha$ is stimulated by the fatty acids and promotes the transcription of ApoA1, CD36, BDNF, and GDNF. Ligand-bound $\mathrm{LXR} \alpha$ in $\mathrm{RXR} / \mathrm{LXR} \alpha$ heterodimer complex can be SUMOylated and inhibit the expression of pro-inflammatory genes such as IL- $1 \beta$ and iNOS

cell clearance [124]. In addition, SUMOylation of LXR $\alpha$ in RXR/LXR $\alpha$ complex has been suggested to cause transrepression of the pro-inflammatory genes by reducing the antibody production [124, 125] (Fig. 3B).

RXRs mediate multiple fatty acid signalling including for DHA following treatment or their dietary intake. These fatty acids are involved in several neural functions including maintaining cognitive integrity and memory-based functions as shown in a study conducted on the BALBcByJ mouse model of schizophrenia [40]. Conversely, DHA and aspirin have also been shown to activate RXR $\alpha$ and PPAR $\alpha$, respectively [126]. DHA inhibited miR-21 and activated PPAR $\alpha$ expression in SH-SY5Y cells and, in combination with aspirin, further activated the RXR/PPAR heterodimer 
leading to increased expression of neurotrophic factors such as brain-derived neurotropic factor (BDNF) and glial cellderived neurotropic factor (GDNF) and postsynaptic density protein 95 (PSD-95) [126] (Fig. 3B).

\section{RXR and Its Partners in Neuronal Differentiation and Neuroprotection}

Next-generation sequencing approaches deployed to dissect the role of RXR in regulating early neural differentiation and specification have led to the identification of RAR $\gamma$, $\mathrm{LXR} \beta$, and RXR $\beta$ as abundantly expressed in undifferentiated embryonic stem cells (ESCs) [127, 128]. Studies have revealed that ligand-dependent activation of RAR/RXR is a dominant inducer of early neurogenesis, while LXR/RXR activation effects are largely limited to early differentiation phases [129]. Accordingly, LXR synthetic agonist GW3965/ LG268 demonstrated remarkable impact on cell fate specification of the neuronal progenitors, initiating axonal guidance and neurogenesis [129]. The effects of RXR-mediated signalling on mouse oligodendrocyte differentiation were also suggested by an almost complete differentiation block induced in oligodendrocyte precursor cells that lack RXR $\gamma$ [130]. In rodents, lysolecithin-induced demyelination of brain slices was associated with the upregulation of RXR $\gamma$ in the cytoplasm of oligodendrocyte lineage cells [14]. Treatment with 9-cis-RA during remyelination process promoted oligodendrocyte differentiation and myelin repair in RXR $\gamma$-dependent manner in vivo [14]. These findings have not only established RXR role in mediating cell differentiation but also highlight RXR functions beyond the nucleus depending on physiological state of the cell [14]. Further, 9-cis-RA-induced RXR $\gamma$ activation is believed to suppress inhibiting factors of the oligodendrocyte differentiation such as LINGO-1, CSPGs, hyaluronic acid, and Wnt/ $\beta$-catenin signalling resulting in OPC maturation [131] (Fig. 4B). RXR signalling may also be relevant for neuroprotective effects on dopaminergic (DA) neurons. RXR heterodimeric partner Nurr1 is expressed in developing and mature DA neurons in several regions of the brain including the hippocampus and cerebral cortex [11]. Nurr1 and other homologous members NGFIB and Nor1 can be activated by hypoxic/ischemic stress and kainic acid-induced excitotoxicity, and its association with RXR can be neuroprotective for DA neuronal cells [80]. It has been demonstrated that Nurr1 agonist mercaptopurine (6-MP) stimulates Nurr1 by direct binding to its N-terminal AF-1 domain [132]. Treatment with 6-MP was shown to reduce the cerebral infarct in a rodent-permanent

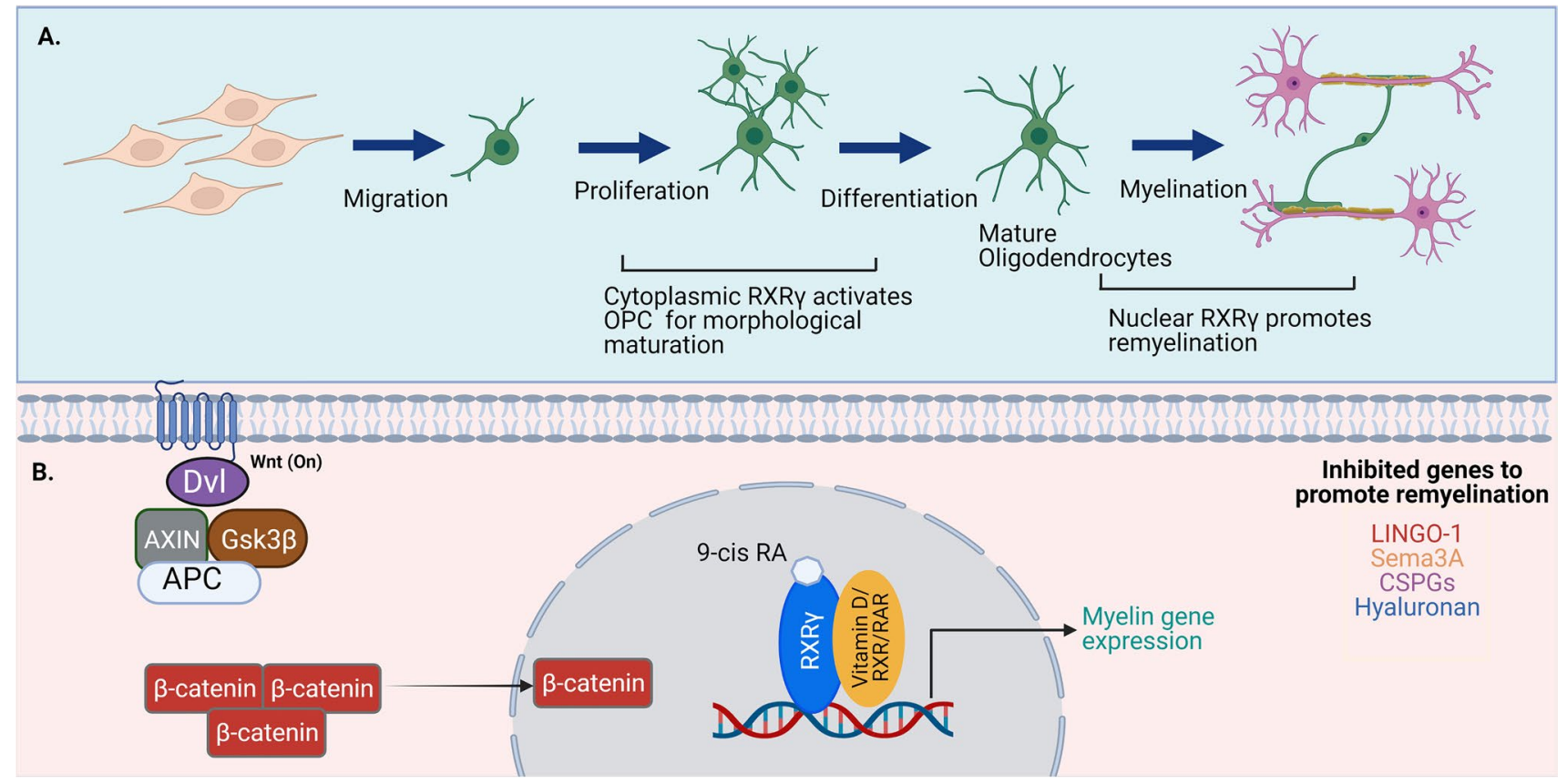

Fig. 4 RXR in neuronal differentiation and neuroprotection. A RXR $\gamma$ expressed in the cytoplasm of the oligodendrocyte precursor cells (OPC) plays an important role in oligodendrocyte differentiation and in promoting remyelination. B In lesioned tissue undergoing remyelination, $\mathrm{RXR} \gamma$ is localised in the nucleus of the myelinating oligodendrocytes and participate in cell maturation and repair. 9-cis-RA treatment stimulates RXR and together with its dimeric interaction with vitamin D receptors promotes remyelination. RXR and its permissive partners compete against the negative modulators of remyelination LINGO-1, Sema3A, chondroitin sulphate proteoglycan (CSPGs), and hyaluronan to repair neuron following injury. Wnt/ $\beta$-signalling also plays a role in the regulation of OPC differentiation and in the stimulation of remyelination 
middle cerebral artery occlusion (pMCAO) model and lead to reduced inflammatory cytokines IL- $1 \beta$ and TNF- $\alpha$ in the serum and CSF [132]. These observations collectively implicate the role of RXR and its partners in regulating neuronal differentiation and mediating neuroprotective effects.

\section{RXR and Its Partners in Regulating Glucose Metabolism}

RXR via heterodimerisation with PPAR $\gamma$ plays crucial role in mediating glycaemic control and regulating cellular and biochemical effects of insulin actions [78]. 9-cisRA concentrations in different feeding, fasting, and glucose challenge conditions to the rodents were inversely associated with a decrease in insulin levels [53]. Glucose utilisation by all cell types fluxes through major pathways in excitatory and inhibitory neurons and astrocytes, via glucose transporters GLUT4 and GLUT3 [133, 134]. RXR participates in adipogenesis by regulating early aspects of GLUT4 responsible for linking adipogenesis to subsequent events of lipid metabolism [135]. RXR agonist, LG268, and PPAR $\gamma$ agonist, rosiglitazone, were shown to generate insulin sensitisation in rodent model of type 2 diabetes via overlapping mechanisms [93, 136]. Similar effects of rosiglitazone and LG268 were identified on the metabolic gene expression in white adipose tissue of skeletal muscle and liver in Zucker diabetic fatty rat models [137]. Rosiglitazone activation led to decreased mRNA expression of the TNF- $\alpha$ in adipose tissue [138]. Further, while rosiglitazone treatment induced mRNA expression of GLUT4, mitochondrial carnitine palmitoyl-transferase (MCPT), stearoyl CoA desaturase 1 (SCD1), and CD36, antagonistic or nil effects were observed upon RXR agonist, LG268 treatment [136, 137] (Fig. 5). In contrast, RXR agonist increased the expression of MCPT, SCD1, and CD36 in the liver, whereas rosiglitazone treatment

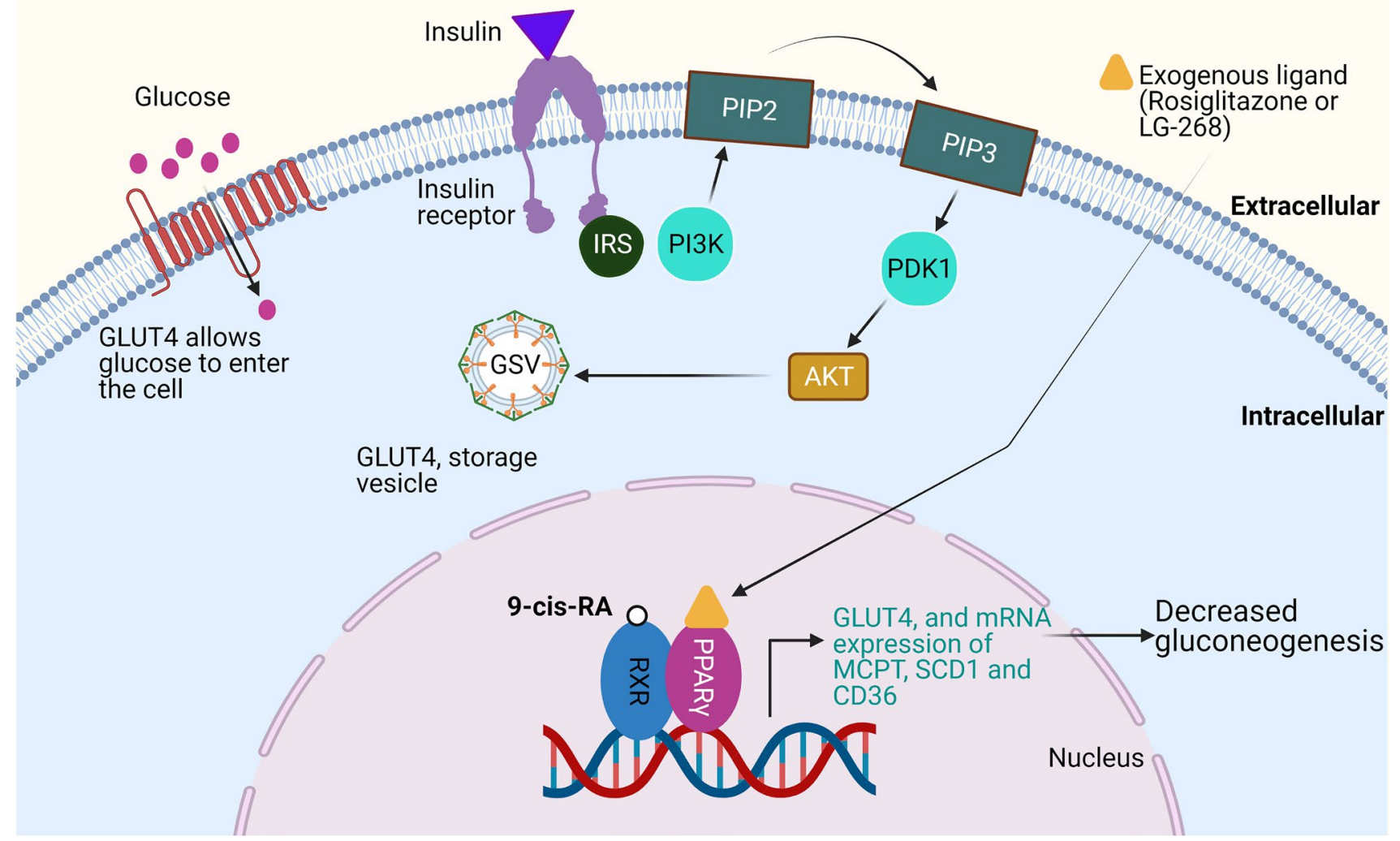

Fig. 5 RXR in glucose metabolism: PPAR $\gamma /$ RXR heterodimer complex is activated by synthetic ligand thiazolidinedione, e.g. rosiglitazone, or by 9 -cis-RA. This activation upregulates the expression of genes involved in glucose metabolism, e.g. glucose transporter (GLUT4) and mRNA expression of MCPT, SCD1, and CD36. The increased expression of GLUT4 mediates insulin signalling pathway and increases the ability of the cells to take up glucose. Insulin binds to its receptor phosphorylated insulin receptor substrate (IRS) which activates and translocate phosphatidylinositol-3-kinase (PI3K) to the plasma membrane, and PI3K phosphorylates phosphatidylinositol 4,5-biphosphate (PIP2) to phosphatidylinositol-3,4,5-biphosphate (PIP3) and then to AKT. AKT promotes translocation of GLUT4 to cell membrane leading to increased glucose uptake. This process stimulates protein synthesis, glycogenesis, and lipogenesis and decrease gluconeogenesis 
only enhanced the expression of CD36 [136]. This differential regulation of genes in adipose and liver tissues is reflective of the fact that insulin sensitisation may be accomplished by multiple mechanisms [136]. In addition, the anti-diabetic effects of RXR agonist may not simply be a reflection of RXR/PPAR $\gamma$ activation, and that permissiveness with interaction partners can vary within different cell and tissue types [136].

\section{RXR and Its Partners in Neurological Disorders}

Cumulative evidence of RXR roles in mediating A $\beta$ clearance, inducing microglial activation and remyelination in different neurological disorders, has generated interest in greater understanding of the RXR signalling in neuronal tissues [11, 68, 139]. The use of RXR agonists and antagonists may help achieve specific modulation of target genes and biochemical networks, which may serve as a promising therapeutic target [48]. A schematic representation of RXR roles and implications of its direct or indirect activation via heterodimer formation and pharmacological stimulation in neurodegenerative diseases is summarised in Fig. 6.

\section{Glaucoma}

Glaucoma is a one of the leading causes of irreversible vision loss and is characterised by progressive degeneration of the retinal ganglion cells (RGCs) and associated optic neuropathy [140]. RXR $\alpha / \beta / \gamma$ isotypes are well expressed in adult ocular tissues including retina, and these receptors also play a critical role in post-natal eye development [141]. Our studies have demonstrated that pharmacological activation of RXR performs a neuroprotective role by rescuing RGCs in murine models of glaucoma [9]. Glaucomatous injury reduced the expression of retinal RXR in both microbead-induced increased intraocular pressure (IOP) model and intravitreal glutamate injection-induced excitotoxicity model [9]. The decrease in RXR expression was

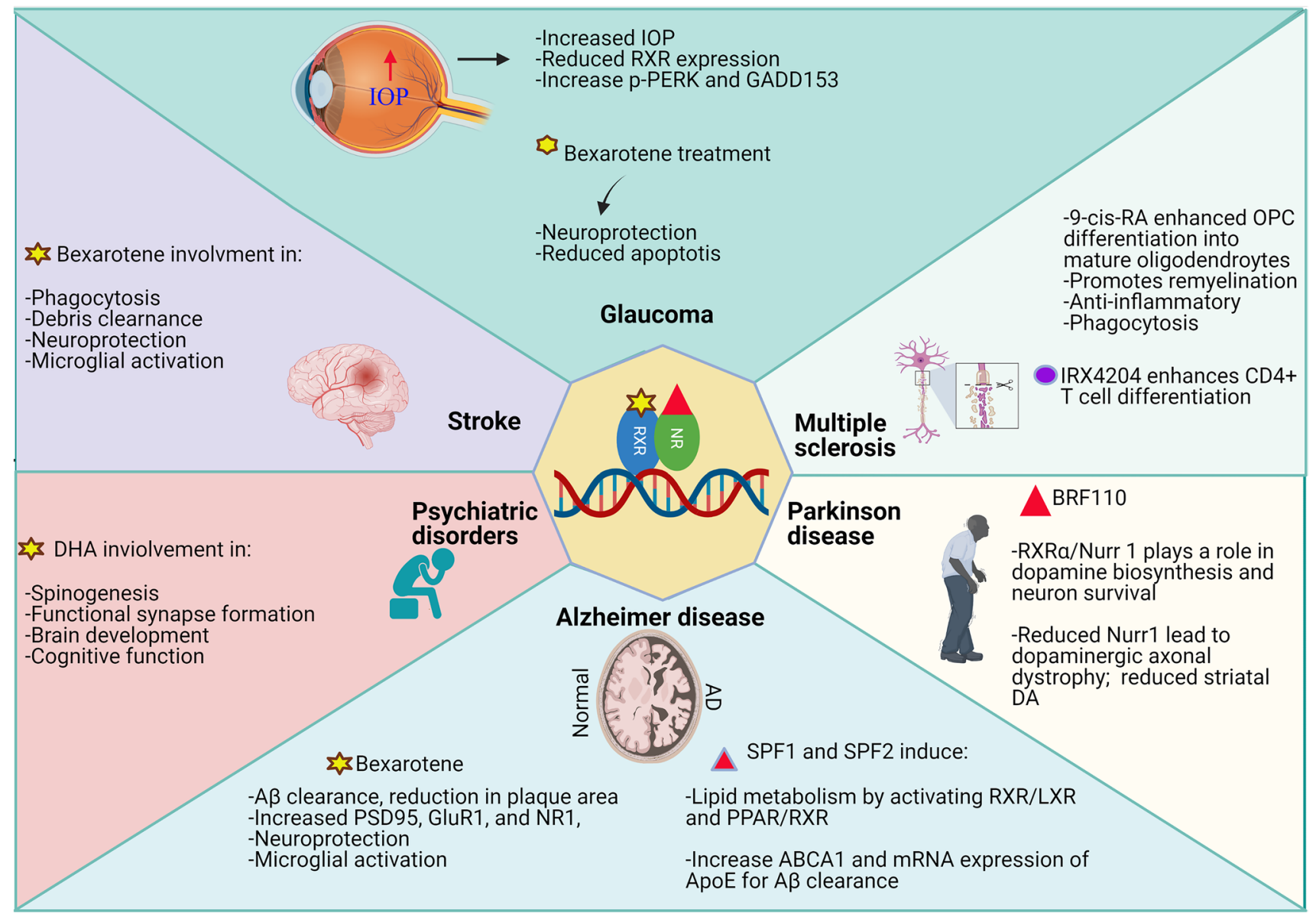

Fig. 6 Schematic representation of functional roles of RXR and its heterodimers upon ligand activation in various neurological disorders 
particularly evident in the inner retinal layers demonstrated using immunohistochemical analysis, where the decline in all the three RXR isotypes was observed [9]. RXR expression was reinstated by treatment with $100 \mathrm{mg} / \mathrm{kg}$ of bexarotene that elicited neuroprotective response in both high IOP and excitotoxicity-induced RGC injury conditions [9]. Bexarotene treatment was also shown to impart protection against ER stress in the retina as evident by the suppression of GADD153 and p-PERK, which are increased in the inner retina in glaucoma [9]. This decrease in ER stress response was concomitant with reduced apoptotic pathway activation in the retina. These findings illustrated that pharmacological activation for RXRs is neuroprotective in the neural retina and prevents functional and structural damage induced by glaucoma injury [9]. Furthermore, HDAC is a constituent of large RXR complex with nuclear receptor corepressor ( $\mathrm{N}-\mathrm{CoR})$, and studies have indicated that HDAC activity is inversely related to RXR activation caused by bexarotene treatment, in glaucoma models [9]. Proteomics analysis of the retinal and vitreous tissues from the post-mortem eyes from open angle glaucoma and aged-matched control eyes showed enrichment of LXR/RXR and FXR/RXR pathways [142, 143]. LXR, RXR, and FXR are important mediators of the lipid signalling including cholesterol metabolism and inflammation indicating the involvement of these biochemical processes in glaucomatous conditions [144]. The enriched LXR/RXR-mediated network components in massspectrometric analysis of glaucoma tissues are suggestive of a potential contribution of RXR in overall pathophysiology of glaucoma.

The effects of RXR have been shown to occur beyond RGCs in the retina and in this regard RXR activation by DHA promoted survival of rat photoreceptors via ERK/ MAPK signalling activation during early development [58]. Supporting these observations, RXR pan-agonists HX630 and PA024 rescued photoreceptors from $\mathrm{H}_{2} \mathrm{O}_{2}$-induced apoptosis in retinal cell cultures [58]. Altogether, these studies suggest that RXR signalling is intricately involved in regulating neuronal survival in glaucoma and potentially other retinal disorders. RXR gene polymorphisms have also been suggested to be associated with diabetic retinopathy [145]. A study evaluated 213 diabetes patients of Han Chinese descent, for 9 different RXR $\gamma$ SNPs, and SNP rs3818569 was found to be enriched in both allele and genotyping frequencies in patients with diabetic retinopathy complications [145]. The exact role of RXR $\gamma$ SNP in the disease pathogenesis is not established, but the reports suggest potential implications in ischemia-mediated overexpression of cytokines [146]. Genome-wide studies for RXR and its partners will unravel their role in determining genetic predisposition in diabetic retinopathy, glaucoma, and other disorders.

\section{RXR in Alzheimer Disease}

Alzheimer disease (AD) is a devastating neurodegenerative disorder of the CNS that causes debilitating memory loss and extensive deterioration of cognitive and functional abilities [12]. The nuclear receptor superfamily, especially $\mathrm{RXR}$, and its agonists have been investigated for their roles in AD pathology [147]. RXR activation has been shown to exert beneficial effects in $\mathrm{AD}$, and the positive impact of RXR actions can be broadly categorised into those mediating $A \beta$ clearance, suppression of $A \beta$ generation, regulation of neuronal function, and anti-inflammatory actions [12, 148]. Bexarotene treatment in APP/PS1 mouse model of $\mathrm{AD}$ was demonstrated to increase clearance of $\mathrm{A} \beta$, which consequently reversed the cognitive impairment caused due to AD pathology $[12,148]$. The RXR ligand treatment induced neuronal differentiation and protected cells against age-related synaptic loss through low-density lipoprotein receptor-related protein-1 (LRP1) [149]. However, the protection conferred by bexarotene needs to be interpreted with caution due to cellular toxicity effects associated with the compound [149]. SPF1 and SPF2, prenylated flavonoids isolated from Sophora tonkinensis gagnep, were also shown to exhibit selective RXR agonistic activity $[68,150]$. These compounds activate RXR/LXR and PPAR/RXR heterodimers and promote ABCA1 and ApoE mRNA expression in PC1 2 cells. The SPF1 and SPF2 treatment protected the cells against $A \beta$-induced neurotoxicity by inducing RXR/ LXR heterodimerisation $[68,150]$.

These observations are supported by the reports that retinoic acid isomers including ATRA, 9-cis-RA, and 13-cisRA induce neuroprotective effects against $A \beta$-induced cell death [151]. Combination treatment with $\operatorname{RAR} \alpha, \beta$-agonist Am80 (tamibarotene), and pan-RXR agonist HX630 significantly improved the memory deficits and suppressed insoluble $\mathrm{A} \beta$ peptide concentrations in the A $\beta \mathrm{PP} 23$ mouse model of AD [152]. More recently, thiophene derivative methyl 2-amino-6-(tert-butyl)-4,5,6,7-tetrahydrobenzo[b]thiophene3-carboxylate (TBTC) which was suggested to function as a preferential agonist of $\operatorname{RXR} \alpha$ and is able to induce heterodimerisation of RXR $\alpha / L X R \alpha$ and PPAR $\gamma / \mathrm{RXR} \alpha$ was demonstrated to reduce $A \beta$ levels in cell culture as well as in AD animal model [153]. Genistein was similarly shown to enhance clearance of $\mathrm{A} \beta$ through PPAR $\gamma / \mathrm{ApoE}$ activation in 8-month-old APP/PS1 mice [154].

These beneficial effects of RXR activation were further supported by the findings that RXR expression in APP/ PS1 mouse model of AD was inversely associated with $A \beta$ immunogenicity in brain hippocampus lysates [10]. Similar effects were recapitulated in SH-SY5Y neuroblastoma cells where treatment with $A \beta$ peptide $(1-42)$ resulted in reduced RXR expression [10]. RXR agonist bexarotene was able to rescue the loss of the RXR expression in cells after 
A $\beta$ (1-42) exposure [10]. RXR-bexarotene also reduced ER stress response and supressed apoptosis in neurons [10]. It was illustrated that the low concentrations of bexarotene exerted neuroprotective effects, alleviating ER stress response, and resulted in reduced cellular apoptosis [10]. Treatment with the compound between 0.1 and $1 \mu \mathrm{M}$ range led to gradual increase in the expression of various RXR isoforms in the cells [10]. In contrast, higher concentration of bexarotene $(5-10 \mu \mathrm{M})$ promoted ER stress marker GADD153 and p-PERK expression [10]. The increase in ER stress response paralleled with the upregulation of pro-apoptotic BAD protein expression at these concentrations [10]. These findings corroborate observations in human AD studies where bexarotene treatment resulted in reduced $A \beta$ levels in brain and enhanced serum $\mathrm{A} \beta$ concentrations, particularly in ApoE4 noncarrier genotype, suggesting that the drug may be acting in ApoE4-dependent manner [155]. Similar effects were observed in 6- and 11-month-old APP/PSEN1 $\mathrm{AD}$ mice where bexarotene treatment reduced insoluble $\mathrm{A} \beta$ levels and diminished $A \beta$ plaque area by approximately $75 \%$. This corresponded with enhanced ApoE, ABCA1, ABCG1, and HDL levels in the hippocampus and cortex tissues [74]. The beneficial effects of RXR agonist in AD were further evident in 5xFAD mouse model where 2-week bexarotene treatment imparted protection to neuronal cells in subiculum and to the layer $\mathrm{V}$ of cortex, rescued memory deficits, and increased pre-and postsynaptic markers, while suppressing neuroinflammation, astrogliosis, and $\mathrm{A} \beta$ plaque formation [12]. The drug also promoted $A \beta$ transcytosis across the membrane in vitro model as well as enhanced flux of $A \beta$ across BBB in ApoE ablated mice, inducing clearance of the peptide and reversing cognitive deficits [156].

\section{Involvement of RXR and Its Interacting Partners in Parkinson Disease Pathology}

Parkinson disease (PD) pathology manifests as tremors, rigidity, gait dysfunction, and bradykinesia [157] and is characterised by selective and progressive degeneration of midbrain dopaminergic neurons in substantia nigra (SN), which results in striatal dopamine deficits [158]. Cumulative evidence suggests that pharmacological activation of RXR induces neurotrophic actions in the brain that may impart protective effects on the neuronal cells [80, 159]. Nurr1, a permissive partner of RXR, has emerged as a major target in PD owing to its pivotal role in the survival of the ventral mesencephalic late dopaminergic precursor neurons [160]. In this regard, Spathis and co-workers (2017) designed a synthetic RXR $\alpha /$ Nurr1 agonist BRF110, for pharmacological activation of Nurr1, which can potentially serve as a monotherapy and has shown promising effects in PD models [11]. In contrast, other two RXR agonists, bexarotene and XCT0135908, showed only limited beneficial effects, with
XCT0135908 demonstrating low penetrability through the BBB [11]. BRF110 effectively prevented the neuronal loss in SH-SY5Y cells in culture and in Nurr1 heterozygous and transgenic mouse models of the PD in vivo [11]. BRF110 specifically activated the Nurr1/RXR $\alpha$ heterodimers, inducing transcription of the dopamine biosynthesising genes such as tyrosine hydroxylase (TH), aromatic l-amino acid decarboxylase (AADC), and GTP cyclohydrolase I (GCH1) transcription and increased striatal dopamine levels [11]. The drug also protected human-induced pluripotent stem cellderived dopaminergic neurons against PD-associated damage at $12 \mu \mathrm{M}$ concentration [11]. Interestingly, a specific RXR agonist IRX4204 induced RXR $\alpha$ /Nurr1 transactivation and promoted $\mathrm{TH}$ expressing dopaminergic neuronal survival in ventral midbrain neuronal cells in a dose-dependent manner [161]. The oral administration of the compound at $10 \mathrm{mg} / \mathrm{kg} /$ day resulted in achieving brain tissue concentration of $11.5 \pm 2.9 \mathrm{nM}$ and translated to diminished PD behavioural phenotype while protecting against DA neuronal loss in a rat model of PD [161]. The treatment also promoted the transcription of neurotropic factor GDNF, suggesting possible avenues for the combinatory therapy in PD [161]. More recently, $\alpha$-synuclein ( $\alpha$-Syn), key protein implicated in PD, has been shown to cross-talk with RXR/RAR and PPAR $\gamma$ induced gene transcription [162]. $\alpha$-Syn was demonstrated to bind to the retinoic acid for translocation to the nucleus in SH-SY5Ycells and induce transcriptional activation [163]. The transcription analysis of SH-SY5Y induced with doxycycline revealed that the nuclear receptors that are activated with retinoic acid were also activated upon $\alpha$-Syn/retinoic acid treatment [163]. The transcription activities associated with RXR $\alpha$, RAR $\beta$, PPAR $\gamma$, LXR, and THR were observed to be enhanced by $\alpha$-Syn/retinoic acid exposure [163]. These findings are mainly derived from in vitro studies, and future in vivo studies will further establish the relevance of these results to the PD pathophysiology [163].

Additionally, RXR and its heterodimeric partner Nur77 have been implicated in the homeostatic regulation of the dopaminergic system, which in addition to PD is intricately linked to schizophrenia, autism, bipolar disorder, depression, and addiction regulation $[164,165]$. Mutations in RXR $\beta$ (Val95Ala), PPAR $\alpha$ (Val227Ala), and nuclear-related receptor 1 (EX8 + 657(CA)9-10) have been identified in neuropsychiatric patients [166]. Further research will elucidate whether pharmacological or genetic regulation of RXR signalling is beneficial in preserving mental health resilience.

\section{Participation of RXR Biochemical Network in Multiple Sclerosis Neuropathology}

Multiple sclerosis (MS) is a heterogeneous neurological disorder characterised by inflammatory changes accompanying progressive demyelination and axonal loss [167]. 
The disease is associated with transient episodes of autoreactive $\mathrm{CD} 4+\mathrm{T}$ cell-mediated inflammatory attacks resulting in loss of myelin sheath and axonal dysfunction [168]. RXR along with its permissive heterodimeric partners plays crucial role in immune cell regulation, inflammation, and oligodendrocyte lineage progression which are important aspects of MS neuropathology [169]. RXR $\alpha$ is expressed by $\mathrm{T}$ cells and other haematopoietic cell types that extensively participate in inflammatory responses [170]. Animal models of demyelination demonstrate increased $\mathrm{RXR} \gamma$ expression in oligodendrocyte lineage cells that are involved in remyelination in MS lesions [14]. This suggests a biochemical compensation by oligodendrocytes to resist the demyelination effects [14]. Blockade of RXR signalling achieved through targeted mRNA silencing, pharmacological antagonism, or null mutation of RXR $\gamma$ revealed inhibition of OPC differentiation and remyelination, but no effects on OPC survival were observed, indicating that RXR signalling may specifically be associated with biochemical mechanisms involved in cell differentiation and myelination [130, 169]. These findings were supported by observations that RXR promoted differentiation of OPCs into mature oligodendrocytes in experimental autoimmune encephalomyelitis (EAE) animal model [171]. Treatment with 9-cis-RA resulted in $\mathrm{RXR} \gamma$ activation and enhanced the differentiation of OPCs into mature oligodendrocytes [14].

Further, RXR signalling is believed to play a vital role in the phagocytic removal of myelin debris by monocytes and macrophages [139]. Myelin fragments produced during demyelination process may inhibit OPC differentiation, thus impairing the remyelination process [139]. Cellular capacity for phagocytic removal of myelin debris decreases with ageing which is also associated with diminished expression of RXR in monocytes and macrophages. Activation of RXR with 9-cis-RA was shown to enhance phagocytosis in ageing macrophages [139]. Bexarotene treatment significantly increased phagocytosis of myelin debris in monocytes in lysolecithin-induced focal demyelination mouse model [139]. Thus, RXR activation may both enhance the OPC differentiation and maturation, as well as induce clearance of myelin debris by monocytes, macrophages, and microglia, processes that are favourable to promote remyelination in MS [131]. Activation of RXR has been shown to supress pathological symptoms observed in animal models of MS [172]. 9-cis-RAmediated activation suppressed astrocytic and microglial pro-inflammatory responses in vivo [173], and drug was shown to reduce the severity of disease in EAE, model [174]. Another highly selective and potent RXR agonist, IRX4204, also demonstrated enhanced differentiation of $\mathrm{CD} 4+\mathrm{T}$ cells into inducible regulatory $\mathrm{T}$ cells (iTreg) while restricting the differentiation of pro-inflammatory $\mathrm{T}$ helper (Th)-17 cells in vitro and effectively attenuated the severity of disease in EAE model [174-176]. Thus, RXR may exert a multipronged influence in MS as receptor signalling plays significant roles in both immunomodulation and remyelination pathways.

\section{Involvement of RXR and Its Heterodimers in Stroke}

RXR is implicated in orchestrating microglial phagocytic functions in the brain and mediate clearance of apoptotic neuronal debris [139]. Macrophages and microglial cells play key roles in removing cellular fragments and protein aggregates that are formed during cellular degeneration and protect against tissue atrophy caused by ischaemic as well as haemorrhagic stroke episodes [13]. As mentioned previously, RXR is widely expressed in macrophages and plays a role in fine-tuning the transcription of several genes [104]. In the microglial cells derived from mouse brain, bexarotene treatment enhanced ApoE, ABCA1, and SREBF2 transcription, which are involved in lipid metabolism, as well as CD36, AXL, MerTK, and TGM2 genes that play key roles in regulating phagocytosis and mediating recovery of damaged tissues [119, 125]. Intriguingly, microglia derived from myeloid cell-specific conditionally ablated RXR $\alpha$ mice demonstrated only limited effects of bexarotene on transcriptional activation of the above-mentioned genes establishing pivotal role of RXR isoform in regulating these biochemical pathways [13]. Further investigations established that microglial and macrophagic ability to induce phagocytosis was impaired upon RXR $\alpha$ ablation, and while bexarotene promoted phagocytic capacity in control cells, the effects were not evident in cells derived from RXR $\alpha$ ablated mice [13]. These findings paralleled with reduced expression of bFGF and VEGF, genes that are implicated in cell/tissue repair and macrophage/microglial markers CD36, CD163, CD204, CD206, and ABCA1 that determine the scavenging function of immune cells, in RXR $\alpha$ impaired cells derived from ischemic mouse brain [13]. Phenotypically RXR $\alpha$ ablated mice depicted significantly greater brain atrophy and neurological deficits compared to the control animals [13]. Bexarotene treatment was able to rescue the post-stroke recuperation in control but not in the RXR $\alpha$-ablated animals [13]. Together, these observations establish key role of RXR $\alpha$ in determining the stroke-mediated damage and beneficial effects of pharmacological modulation of RXR in imparting protection against these deficits [13].

Further, Nurr1 heterodimerisation with RXR has been shown to confer neuroprotection and provide anti-inflammatory effects through NF- $\mathrm{KB}$ inhibitory actions in middle cerebral artery occlusion ischemic stroke model [177]. Nurr1/RXR agonist HX600 protected against motor impairment in mice and reduced microglial pro-inflammatory mediators preventing inflammation-induced neuronal 
death in co-cultured neuronal and microglia in vitro model [177]. Administration of HX600 to ischemia mouse model resulted in the downregulation of Iba1, p38, and TREM2 markers and reduced lyso-phosphatidylcholine and acylcarnitine lipid metabolites [177]. The treatment was also effective in imparting protection to endogenous microglia from ischemia-induced apoptosis and prevented leukocyte infiltration into the tissue [177]. Nurr1/RXR may therefore provide novel mechanism-based targets in addressing the neuroinflammatory aspects in stroke.

\section{Clinical Trials Focussing on Use of RXR and Its Agonists}

RXR and its partners are being investigated in several clinical trials for use as a potential drug target in AD and PD. A look at the (https://clinicaltrials.gov/ as of 6th August 2021) registry illustrates 20 clinical trials that are listed in the repository, with status as either completed (11), currently recruiting (3), or terminated (2), with the remainder as not recruiting or are with unknown status. Amongst these, a phase 2 clinical trial conducted by Cleveland Clinic (NCT01782742, Las Vegas, Nevada) evaluated the efficacy and safety of RXR agonist bexarotene in patients suffering from mild to moderate AD. The primary outcome of the Brain Energy for Amyloid Transformation in AD or BEATAD study was measured using $18 \mathrm{~F}-\mathrm{AV}-45$ positron emission tomography (PET) imaging of brain for $A \beta$ load. No changes in brain amyloid load were observed in ApoE carriers, while ApoE non-carriers depicted a decrease in brain amyloid load [148]. However, the overall outcome of this study was negative, and even though bexarotene reduced $A \beta$ levels in ApoE non-carriers, it resulted in elevated triglycerides presenting a cardiovascular risk [148].

Another study sponsored by ReXceptor, Inc. (NCT02061878, Orlando, Florida) aimed to determine whether bexarotene treatment in humans alters the CSF levels of ApoE or clearance of $A \beta$ peptide [155]. The study only included 12 participants, and the results were not published in the public domain [155]. Next, a phase 1 clinical trial sponsored by Lo therapeutics (NCT02438215, Molecular NeuroImaging, New Haven, Connecticut) on RXR agonist IRX4204, a potent and selective BBB penetrant, was conducted to examine dopamine transporter density using [123I] $\beta$-CIT single-photon emission tomography (SPECT) before and following treatment with drug [178]. Changes in motor and cognitive parameters were also studied for a 30-day period in 15 early PD subjects in this study [178]. The study indicated safe use and tolerance at dosage of 5 and $10 \mathrm{mg} /$ day for 30 days with no short-term effects on the dopamine transporter binding [178]. We anticipate that results of at least some of these studies will help design further large-scale randomised clinical trials on drugs targeting RXR effects in the neurological disorders. A potential limitation is that different regions of the brain and various cell types can be affected differently and whole-brain imaging may not be able to detect subtle changes induced by RXR agonist treatment.

\section{Concluding Remarks and Future Perspectives}

RXRs and their interacting partners play a pivotal role in regulating cellular and biochemical processes relevant to neuronal health, and this positions the receptor family members and their downstream signalling as a potential therapeutic target in multiple neurological disorders. RXR activation is instrumental in fine-tuning the transcription of several genes which means that these receptors mediate critical nodes that lie at the crossroads of key biochemical networks. Alterations in expression of various RXR isoforms, their downstream signalling, and regulatory molecules including their endogenous ligands have been detected in disease conditions. Studies focussing on the activation of RXR via 9-cis-DHRA and DHA ligands can potentially provide mechanistic insights into specific functioning of RXR isotypes in CNS. There is evidence to indicate that RXR activation in heterodimeric complex enhances the expression of neurotrophic factors such as BDNF and GDNF, which have established neuroprotective roles [126]. Thus, it is likely that a proportion of RXR-induced effects is mediated through its influence on bolstering expression of neurotrophic factors in CNS. RXR and its heterodimeric partners, however, have been implicated in regulating host of additional biochemical and metabolic responses such as glucose and cholesterol metabolism and in maintaining overall neuronal physiology and may have effects independent of neurotrophic factor mediated actions.

Studies in transgenic and knockout animal models have indicated that global ablation of the $\mathrm{RXR} \alpha^{-1-}$ results into an embryonic lethal phenotype; however, compound $\mathrm{RXR} \alpha^{+/-}, \mathrm{RXR} \beta^{-/-}$, and $\mathrm{RXR} \gamma^{-/-}$knockout mice survive and can be utilised to investigate development related and functional roles of these receptors in vivo [179]. Several interacting partners of RXR have been identified in the recent years, and future investigations will facilitate identification of the novel cell and organelle-specific partners of RXR in health and disease conditions. While traditionally immune precipitation-based methods have been used to identify the interacting partners, mass spectrometrybased proteomics methods coupled with ChIP assay will provide a high-throughput approach to determine novel protein-protein and DNA-protein interactions. Further, 
RXR-focussed computational and bioinformatic studies will help identify novel and more specific ligands that could rationalise drug development. This could also help in the development of synthetic and naturally occurring ligands leading to improved BBB permeability. A significant limitation in RXR research arises from its biochemical and functional redundancy with other nuclear receptor family members. This coupled with overlapping ligand recognition and transcription activation adds to the complexity to understand the RXR biology in a cell- and tissue-specific manner. Designing or identification of specific ligands for individual RXR isotypes will help understand receptor mechanism as well as develop CNS targeted treatment strategies.

Acknowledgements We acknowledge all the scientific contributions made in the field of RXR biology and apologise for not being able to cite other potentially relevant references.

Author Contribution All the authors contributed to the conception, design of the manuscript, and literature review. The figures were designed and prepared by SS* and NC. All the authors discussed, reviewed, and approved the final manuscript.

Funding Open Access funding enabled and organized by CAUL and its Member Institutions This work is supported by the National Health and Medical Research Council (NHMRC) Australia, Macquarie University, Perpetual Hilcrest, Ophthalmic Research Institute of Australia (ORIA), National Multiple Sclerosis Society (NMSS), USA, and La Fondation pour l'aide à la recherche sur la sclérose en plaques (ARSEP), France.

Availability of Data and Material Not applicable.

\section{Declarations}

Ethics Approval and Consent to Participate Not applicable.

\section{Consent for Publication Yes.}

Competing Interests The authors declare no conflict of interest. W. $\mathrm{K}$. is an inventor of the patent family "Precursor compounds for providing retinoids of the vitamin A5 pathway and uses thereof" PCT/ HU2017/091937, US16102137, 127356JP-18340, 127578AU-18340, $127579 \mathrm{CN}-18340$, and $128446 \mathrm{CA}-18340$. W. K. is a shareholder of CISCAREX UG.

Open Access This article is licensed under a Creative Commons Attribution 4.0 International License, which permits use, sharing, adaptation, distribution and reproduction in any medium or format, as long as you give appropriate credit to the original author(s) and the source, provide a link to the Creative Commons licence, and indicate if changes were made. The images or other third party material in this article are included in the article's Creative Commons licence, unless indicated otherwise in a credit line to the material. If material is not included in the article's Creative Commons licence and your intended use is not permitted by statutory regulation or exceeds the permitted use, you will need to obtain permission directly from the copyright holder. To view a copy of this licence, visit http://creativecommons.org/licenses/by/4.0/.

\section{References}

1. Sever R, Glass CK (2013) Signaling by nuclear receptors. Cold Spring Harb Perspect Biol 5(3):a016709. https://doi.org/10.1101/ cshperspect.a016709

2. Szanto A, Narkar V, Shen Q, Uray IP, Davies PJ, Nagy L (2004) Retinoid X receptors: X-ploring their (patho)physiological functions. Cell Death Differ 11(Suppl 2):S126-143. https://doi.org/ 10.1038/sj.cdd.4401533

3. Dawson MI (1821) Xia Z (2012) The retinoid X receptors and their ligands. Biochim Biophys Acta 1:21-56. https://doi.org/10. 1016/j.bbalip.2011.09.014

4. Rőszer T, Menéndez-Gutiérrez MP, Cedenilla M, Ricote M (2013) Retinoid X receptors in macrophage biology. Trends Endocrinol Metab 24(9):460-468

5. Evans RM, Mangelsdorf DJ (2014) Nuclear receptors, RXR, and the Big Bang. Cell 157(1):255-266. https://doi.org/10.1016/j. cell.2014.03.012

6. Westin S, Kurokawa R, Nolte RT, Wisely GB, McInerney EM, Rose DW, Milburn MV, Rosenfeld MG, Glass CK (1998) Interactions controlling the assembly of nuclear-receptor heterodimers and co-activators. Nature 395(6698):199-202. https://doi.org/10. $1038 / 26040$

7. Krezel W, Kastner P, Chambon P (1999) Differential expression of retinoid receptors in the adult mouse central nervous system. Neuroscience 89(4):1291-1300. https://doi.org/10.1016/s03064522(98)00342-x

8. McFarland K, Spalding TA, Hubbard D, Ma JN, Olsson R, Burstein ES (2013) Low dose bexarotene treatment rescues dopamine neurons and restores behavioral function in models of Parkinson's disease. ACS Chem Neurosci 4(11):1430-1438. https://doi.org/10.1021/cn400100f

9. Dheer Y, Chitranshi N, Gupta V, Sharma S, Pushpitha K, Abbasi M, Mirzaei M, You Y, Graham SL, Gupta V (2019) Retinoid x receptor modulation protects against ER stress response and rescues glaucoma phenotypes in adult mice. Exp Neurol 314:111125. https://doi.org/10.1016/j.expneurol.2019.01.015

10. Dheer Y, Chitranshi N, Gupta V, Abbasi M, Mirzaei M, You Y, Chung R, Graham SL, Gupta V (2018) Bexarotene modulates retinoid-X-receptor expression and is protective against neurotoxic endoplasmic reticulum stress response and apoptotic pathway activation. Mol Neurobiol 55(12):9043-9056

11. Spathis AD, Asvos X, Ziavra D, Karampelas T, Topouzis S, Cournia Z, Qing X, Alexakos P, Smits LM, Dalla C, Rideout HJ, Schwamborn JC, Tamvakopoulos C, Fokas D, Vassilatis DK (2017) Nurr1:RXRalpha heterodimer activation as monotherapy for Parkinson's disease. Proc Natl Acad Sci U S A 114(15):39994004. https://doi.org/10.1073/pnas.1616874114

12. Mariani MM, Malm T, Lamb R, Jay TR, Neilson L, Casali B, Medarametla L, Landreth GE (2017) Neuronally-directed effects of RXR activation in a mouse model of Alzheimer's disease. Sci Rep 7:42270. https://doi.org/10.1038/srep42270

13. Ting S-M, Zhao X, Sun G, Obertas L, Ricote M, Aronowski J (2020) Brain cleanup as a potential target for poststroke recovery: the role of RXR (Retinoic X Receptor) in phagocytes. Stroke 51(3):958-966

14. Huang JK, Jarjour AA, Oumesmar BN, Kerninon C, Williams A, Krezel W, Kagechika H, Bauer J, Zhao C, Baron-Van Evercooren A (2011) Retinoid X receptor gamma signaling accelerates CNS remyelination. Nat Neurosci 14(1):45-53

15. Mangelsdorf DJ, Ong ES, Dyck JA, Evans RM (1990) Nuclear receptor that identifies a novel retinoic acid response pathway. Nature 345(6272):224-229. https://doi.org/10.1038/345224a0

16. Rühl R, Krzyżosiak A, Niewiadomska-Cimicka A, Rochel N, Szeles L, Vaz B, Wietrzych-Schindler M, Álvarez S, Szklenar 
M, Nagy L (2015) 9-cis-13, 14-dihydroretinoic acid is an endogenous retinoid acting as RXR ligand in mice. PLoS Genet 11(6):e1005213

17. Germain P, Chambon P, Eichele G, Evans RM, Lazar MA, Leid M, De Lera AR, Lotan R, Mangelsdorf DJ, Gronemeyer H (2006) International Union of Pharmacology. LXIII Retinoid X receptors Pharmacol Rev 58(4):760-772. https://doi.org/10.1124/pr. 58.4 .7

18. Shulman AI, Mangelsdorf DJ (2005) Retinoid x receptor heterodimers in the metabolic syndrome. $\mathrm{N}$ Engl $\mathrm{J}$ Med 353(6):604-615

19. Bridgham JT, Eick GN, Larroux C, Deshpande K, Harms MJ, Gauthier ME, Ortlund EA, Degnan BM, Thornton JW (2010) Protein evolution by molecular tinkering: diversification of the nuclear receptor superfamily from a ligand-dependent ancestor. PLoS Biol 8 (10). doi:https://doi.org/10.1371/journal.pbio.10004 97

20. Fonseca E, Machado AM, Vilas-Arrondo N, Gomes-dos-Santos A, Veríssimo A, Esteves P, Almeida T, Themudo G, Ruivo R, Pérez M (2020) Cartilaginous fishes offer unique insights into the evolution of the nuclear receptor gene repertoire in gnathostomes. General and Comparative Endocrinology 295:113527

21. Xu EH, Lambert MH (2003) Structural insights into regulation of nuclear receptors by ligands. Nucl Recept Signal 1:e004. https:// doi.org/10.1621/nrs.01004

22. Gampe RT Jr, Montana VG, Lambert MH, Miller AB, Bledsoe RK, Milburn MV, Kliewer SA, Willson TM, Xu HE (2000) Asymmetry in the PPARgamma/RXRalpha crystal structure reveals the molecular basis of heterodimerization among nuclear receptors. Mol Cell 5(3):545-555. https://doi.org/10.1016/s10972765(00)80448-7

23. Chandra V, Huang P, Hamuro Y, Raghuram S, Wang Y, Burris TP, Rastinejad F (2008) Structure of the intact PPAR-gammaRXR- nuclear receptor complex on DNA. Nature 456(7220):350 356. https://doi.org/10.1038/nature07413

24. Rastinejad F, Wagner T, Zhao Q, Khorasanizadeh S (2000) Structure of the RXR-RAR DNA-binding complex on the retinoic acid response element DR1. EMBO J 19(5):1045-1054. https://doi. org/10.1093/emboj/19.5.1045

25. Bourguet W, Vivat V, Wurtz JM, Chambon P, Gronemeyer H, Moras D (2000) Crystal structure of a heterodimeric complex of RAR and RXR ligand-binding domains. Mol Cell 5(2):289-298. https://doi.org/10.1016/s1097-2765(00)80424-4

26. Rochel N, Ciesielski F, Godet J, Moman E, Roessle M, PelusoIltis C, Moulin M, Haertlein M, Callow P, Mely Y, Svergun DI, Moras D (2011) Common architecture of nuclear receptor heterodimers on DNA direct repeat elements with different spacings. Nat Struct Mol Biol 18(5):564-570. https://doi.org/10.1038/ nsmb. 2054

27. Nagy L, Schwabe JW (2004) Mechanism of the nuclear receptor molecular switch. Trends Biochem Sci 29(6):317-324. https:// doi.org/10.1016/j.tibs.2004.04.006

28. Batista MR, Martinez L (2013) Dynamics of nuclear receptor Helix-12 switch of transcription activation by modeling timeresolved fluorescence anisotropy decays. Biophys J 105(7):16701680. https://doi.org/10.1016/j.bpj.2013.07.032

29. Bourguet W, Ruff M, Chambon P, Gronemeyer H, Moras D (1995) Crystal structure of the ligand-binding domain of the human nuclear receptor RXR- $\alpha$. Nature 375(6530):377-382

30. Osz J, McEwen AG, Bourguet M, Przybilla F, Peluso-Iltis C, Poussin-Courmontagne P, Mely Y, Cianferani S, Jeffries CM, Svergun DI, Rochel N (2020) Structural basis for DNA recognition and allosteric control of the retinoic acid receptors RARRXR. Nucleic Acids Res 48(17):9969-9985. https://doi.org/10. 1093/nar/gkaa697
31. Rastinejad F, Huang P, Chandra V, Khorasanizadeh S (2013) Understanding nuclear receptor form and function using structural biology. J Mol Endocrinol 51(3):T1-T21. https://doi.org/ 10.1530/JME-13-0173

32. UniProt C (2021) UniProt: the universal protein knowledgebase in 2021. Nucleic Acids Res 49(D1):D480-D489. https://doi.org/ 10.1093/nar/gkaa1100

33. Lefebvre P, Benomar Y, Staels B (2010) Retinoid X receptors: common heterodimerization partners with distinct functions. Trends Endocrinol Metab 21(11):676-683. https://doi.org/10. 1016/j.tem.2010.06.009

34. Numasawa T, Koga H, Ueyama K, Maeda S, Sakou T, Harata S, Leppert M, Inoue I (1999) Human retinoic X receptor beta: complete genomic sequence and mutation search for ossification of posterior longitudinal ligament of the spine. J Bone Miner Res 14(4):500-508. https://doi.org/10.1359/jbmr.1999.14.4.500

35. Fleischhauer K, Park J, DiSanto J, Marks M, Ozato K, Yang S (1992) Isolation of a full-length cDNA clone encoding a N-terminally variant form of the human retinoid $\mathrm{X}$ receptor beta. Nucleic Acids Research 20 (7):1801

36. Fujita A, Mitsuhashi T (1999) Differential regulation of liganddependent and ligand-independent functions of the mouse retinoid $\mathrm{X}$ receptor $\beta$ by alternative splicing. Biochem Biophys Res Commun 255(3):625-630

37. Bookout AL, Jeong Y, Downes M, Ruth TY, Evans RM, Mangelsdorf DJ (2006) Anatomical profiling of nuclear receptor expression reveals a hierarchical transcriptional network. Cell 126(4):789-799

38. Liu Q, Linney E (1993) The mouse retinoid-X receptor-gamma gene: genomic organization and evidence for functional isoforms. Mol Endocrinol 7(5):651-658

39. Wietrzych M, Meziane H, Sutter A, Ghyselinck N, Chapman PF, Chambon P, Krezel W (2005) Working memory deficits in retinoid X receptor gamma-deficient mice. Learn Mem 12(3):318326. https://doi.org/10.1101/lm.89805

40. Wietrzych-Schindler M, Szyszka-Niagolov M, Ohta K, Endo Y, Pérez E, de Lera AR, Chambon P, Krezel W (2011) Retinoid x receptor gamma is implicated in docosahexaenoic acid modulation of despair behaviors and working memory in mice. Biol Psychiat 69(8):788-794

41. Macoritto M, Nguyen-Yamamoto L, Huang DC, Samuel S, Yang XF, Wang TT, White JH, Kremer R (2008) Phosphorylation of the human retinoid $\mathrm{X}$ receptor $\alpha$ at serine 260 impairs coactivator (s) recruitment and induces hormone resistance to multiple ligands. J Biol Chem 283(8):4943-4956

42. Gianní M, Tarrade A, Nigro EA, Garattini E, Rochette-Egly C (2003) The AF-1 and AF-2 domains of RAR $\gamma 2$ and RXR $\alpha$ cooperate for triggering the transactivation and the degradation of RAR $\gamma 2 / R X R \alpha$ heterodimers. J Biol Chem 278(36):34458-34466

43. Bridgham JT, Eick GN, Larroux C, Deshpande K, Harms MJ, Gauthier ME, Ortlund EA, Degnan BM, Thornton JW (2010) Protein evolution by molecular tinkering: diversification of the nuclear receptor superfamily from a ligand-dependent ancestor. PLoS biology 8(10):e1000497

44. Novotný JP, Chughtai AA, Kostrouchová M, Kostrouchová V, Kostrouch D, Kaššák F, Kaňa R, Schierwater B, Kostrouchová M, Kostrouch Z (2017) Trichoplax adhaerens reveals a network of nuclear receptors sensitive to 9-cis-retinoic acid at the base of metazoan evolution. PeerJ 5:e3789

45. de Groot A, de Rosny E, Juillan-Binard C, Ferrer J-L, Laudet V, Pierce RJ, Pebay-Peyroula E, Fontecilla-Camps JC, Borel F (2005) Crystal structure of a novel tetrameric complex of agonist-bound ligand-binding domain of Biomphalaria glabrata retinoid X receptor. J Mol Biol 354(4):841-853 
46. Reitzel AM, Macrander J, Mane-Padros D, Fang B, Sladek FM, Tarrant AM (2018) Conservation of DNA and ligand binding properties of retinoid $\mathrm{X}$ receptor from the placozoan Trichoplax adhaerens to human. J Steroid Biochem Mol Biol 184:3-10

47. de Lera ÁR, Krezel W, Rühl R (2016) An endogenous mammalian retinoid $\mathrm{X}$ receptor ligand, at last! ChemMedChem 11(10):1027-1037

48. Krezel W, Ruhl R, de Lera AR (2019) Alternative retinoid X receptor (RXR) ligands. Mol Cell Endocrinol 491:110436. https://doi.org/10.1016/j.mce.2019.04.016

49. Markov GV, Girard J, Laudet V, Leblanc C (2018) Hormonally active phytochemicals from macroalgae: a largely untapped source of ligands to deorphanize nuclear receptors in emerging marine animal models. Gen Comp Endocrinol 265:41-45

50. Huang P, Chandra V, Rastinejad F (2014) Retinoic acid actions through mammalian nuclear receptors. Chem Rev 114(1):233254. https://doi.org/10.1021/cr400161b

51. Kane MA, Folias AE, Wang C, Napoli JL (2008) Quantitative profiling of endogenous retinoic acid in vivo and in vitro by tandem mass spectrometry. Anal Chem 80(5):1702-1708

52. Heyman RA, Mangelsdorf DJ, Dyck JA, Stein RB, Eichele G, Evans RM, Thaller C (1992) 9-cis retinoic acid is a high affinity ligand for the retinoid $\mathrm{X}$ receptor. Cell 68(2):397-406

53. Kane MA, Folias AE, Pingitore A, Perri M, Obrochta KM, Krois CR, Cione E, Ryu JY, Napoli JL (2010) Identification of 9-cis-retinoic acid as a pancreas-specific autacoid that attenuates glucose-stimulated insulin secretion. Proc Natl Acad Sci 107(50):21884-21889

54. Dmetrichuk JM, Carlone RL, Jones TR, Vesprini ND, Spencer GE (2008) Detection of endogenous retinoids in the molluscan CNS and characterization of the trophic and tropic actions of 9-cis retinoic acid on isolated neurons. J Neurosci 28(48):13014-13024

55. Durand B, Saunders M, Leroy P, Leid M, Chambon P (1992) Alltrans and 9-cis retinoic acid induction of CRABPII transcription is mediated by RAR-RXR heterodimers bound to DR1 and DR2 repeated motifs. Cell 71(1):73-85

56. de Urquiza AM, Liu S, Sjöberg M, Zetterström RH, Griffiths W, Sjövall J, Perlmann T (2000) Docosahexaenoic acid, a ligand for the retinoid $\mathrm{X}$ receptor in mouse brain. Science 290(5499):2140-2144

57. Calderon F, Kim H-Y (2007) Role of RXR in neurite outgrowth induced by docosahexaenoic acid. Prostaglandins Leukot Essent Fatty Acids 77(5-6):227-232

58. German OL, Monaco S, Agnolazza DL, Rotstein NP, Politi LE (2013) Retinoid X receptor activation is essential for docosahexaenoic acid protection of retina photoreceptors. J Lipid Res 54(8):2236-2246

59. Lemotte PK, Keidel S, Apfel CM (1996) Phytanic acid is a retinoid X receptor ligand. Eur J Biochem 236(1):328-333

60. Zomer AW, Jansen GA, van der Burg B, Verhoeven NM, Jakobs C, van der Saag PT, Wanders RJ, Poll-The BT (2000) PhytanoylCoA hydroxylase activity is induced by phytanic acid. Eur J Biochem 267(13):4063-4067

61. Seedorf U, Raabe M, Ellinghaus P, Kannenberg F, Fobker M, Engel T, Denis S, Wouters F, Wirtz KW, Wanders RJ (1998) Defective peroxisomal catabolism of branched fatty acyl coenzyme A in mice lacking the sterol carrier protein-2/sterol carrier protein-x gene function. Genes Dev 12(8):1189-1201

62. Jung C-G, Horike H, Cha B-Y, Uhm K-O, Yamauchi R, Yamaguchi T, Hosono T, Iida K, Woo J-T, Michikawa M (2010) Honokiol increases ABCA1 expression level by activating retinoid $\mathrm{X}$ receptor beta. Biol Pharm Bull 33(7):1105-1111

63. Atanasov AG, Wang JN, Gu SP, Bu J, Kramer MP, Baumgartner L, Fakhrudin N, Ladurner A, Malainer C, Vuorinen A (2013) Honokiol: a non-adipogenic PPAR $\gamma$ agonist from nature.
Biochimica et Biophysica Acta (BBA)-General Subjects 1830 (10):4813-4819

64. Chen F, Ghosh A, Hu M, Long Y, Sun H, Kong L, Hong H, Tang

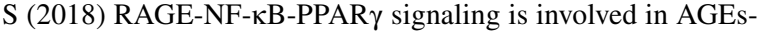
induced upregulation of amyloid- $\beta$ influx transport in an in vitro BBB model. Neurotox Res 33(2):284-299

65. Wang W, Chen M, Jin X, Li X, Yang Z, Lin H, Xu S (2018) H2S induces Th1/Th2 imbalance with triggered NF- $\mathrm{KB}$ pathway to exacerbate LPS-induce chicken pneumonia response. Chemosphere 208:241-246

66. Zhang H, Xu X, Chen L, Chen J, Hu L, Jiang H, Shen X (2011) Molecular determinants of magnolol targeting both RXR $\alpha$ and PPAR $\gamma$. PloS one 6(11):e28253

67. Nakashima K-i, Murakami T, Tanabe H, Inoue M (2014) Identification of a naturally occurring retinoid $\mathrm{X}$ receptor agonist from Brazilian green propolis. Biochimica et Biophysica Acta (BBA)-General Subjects 1840 (10):3034-3041

68. Wang W, Nakashima K-I, Hirai T, Inoue M (2019) Neuroprotective effect of naturally occurring RXR agonists isolated from Sophora tonkinensis Gagnep on amyloid- $\beta$-induced cytotoxicity in PC12 cells. Journal of Natural Medicines 73(1):154-162

69. Li M, Yue GG-L, Song L-H, Huang M-B, Lee JK-M, Tsui SK-W, Fung K-P, Tan N-H, Bik-San Lau C (2018) Natural small molecule bigelovin suppresses orthotopic colorectal tumor growth and inhibits colorectal cancer metastasis via IL6/STAT3 pathway. Biochem Pharmacol 150:191-201

70. Merk D, Grisoni F, Friedrich L, Schneider G (2018) Tuning artificial intelligence on the de novo design of natural-productinspired retinoid $\mathrm{X}$ receptor modulators. Communications Chemistry $1(1): 1-9$

71. Tanaka T, De Luca LM (2009) Therapeutic potential of "rexinoids" in cancer prevention and treatment. Can Res 69(12):4945-4947

72. Boehm MF, Zhang L, Zhi L, McClurg MR, Berger E, Wagoner M, Mais DE, Suto CM, Davies PJ, Heyman RAJJomc (1995) Design and synthesis of potent retinoid X receptor selective ligands that induce apoptosis in leukemia cells. 38 (16):3146-3155

73. Chitranshi N, Dheer Y, Kumar S, Graham SL, Gupta V (2019) Molecular docking, dynamics, and pharmacology studies on bexarotene as an agonist of ligand-activated transcription factors, retinoid X receptors. J Cell Biochem 120(7):11745-11760

74. Crunkhorn S (2012) RXR agonist reverses Alzheimer's disease. Nat Rev Drug Discovery 11(4):271-271

75. Cramer PE, Cirrito JR, Wesson DW, Lee CD, Karlo JC, Zinn AE, Casali BT, Restivo JL, Goebel WD, James MJ (2012) ApoEdirected therapeutics rapidly clear $\beta$-amyloid and reverse deficits in AD mouse models. Science 335(6075):1503-1506

76. Ishihara Y, Sakurai H, Oguro A, Tsuji M, Vogel CF, Yamazaki $\mathrm{T}$ (2019) Retinoid X receptor-mediated neuroprotection via CYP19 upregulation and subsequent increases in estradiol synthesis. The Journal of steroid biochemistry and molecular biology 193:105421

77. Menéndez-Gutiérrez MP, Rőszer T, Fuentes L, Núñez V, Escolano A, Redondo JM, De Clerck N, Metzger D, Valledor AF, Ricote MJTJoci (2015) Retinoid X receptors orchestrate osteoclast differentiation and postnatal bone remodeling. 125 (2):809-823

78. Cesario RM, Klausing K, Razzaghi H, Crombie D, Rungta D, Heyman RA, Lala DSJME (2001) The rexinoid LG100754 is a novel RXR: PPAR $\gamma$ agonist and decreases glucose levels in vivo. 15 (8):1360-1369

79. Kakuta H, Ohsawa F, Yamada S, Makishima M, Tai A, Yasui H, Yoshikawa YJB, Bulletin P (2012) Feasibility of structural modification of retinoid $\mathrm{X}$ receptor agonists to separate blood glucose-lowering action from adverse effects: studies in KKAy type 2 diabetes model mice. 35 (4):629-633 
80. Wallén-Mackenzie Å, de Urquiza AM, Petersson S, Rodriguez FJ, Friling S, Wagner J, Ordentlich P, Lengqvist J, Heyman RA, Arenas E (2003) Nurr1-RXR heterodimers mediate RXR ligand-induced signaling in neuronal cells. Genes Dev 17(24):3036-3047

81. Morita K, Kawana K, Sodeyama M, Shimomura I, Kagechika H, Makishima MJBp (2005) Selective allosteric ligand activation of the retinoid $X$ receptor heterodimers of NGFI-B and Nurr1. 71 (1-2):98-107

82. Xu T, Yu X, Ou S, Liu X, Yuan J, Chen YJCd (2017) Statin adherence and the risk of stroke: a dose-response meta-analysis. 31 (4):263-271

83. Chen J, Costa LG, Guizzetti MJJoP, Therapeutics E (2011) Retinoic acid isomers up-regulate ATP binding cassette A1 and G1 and cholesterol efflux in rat astrocytes: implications for their therapeutic and teratogenic effects. 338 (3):870-878

84. Kintscher U, Goetze S, Wakino S, Kim S, Nagpal S, Chandraratna RA, Graf K, Fleck E, Hsueh WA, Law RE (2000) Peroxisome proliferator-activated receptor and retinoid $\mathrm{X}$ receptor ligands inhibit monocyte chemotactic protein-1-directed migration of monocytes. Eur J Pharmacol 401(3):259-270

85. Liang Y, Lin S, Beyer TP, Zhang Y, Wu X, Bales KR, DeMattos RB, May PC, Li SD, Jiang XC (2004) A liver X receptor and retinoid $\mathrm{X}$ receptor heterodimer mediates apolipoprotein $\mathrm{E}$ expression, secretion and cholesterol homeostasis in astrocytes. J Neurochem 88(3):623-634

86. Zhang-Gandhi CX, Drew PD (2007) Liver X receptor and retinoid $\mathrm{X}$ receptor agonists inhibit inflammatory responses of microglia and astrocytes. J Neuroimmunol 183(1-2):50-59

87. de la Fuente A, Errea O, van Wijngaarden P, Gonzalez G, Kerninon C, Jarjour A, Lewis H, Jones C, Nait-Oumesmar B, Zhao C, ffrench-Constant C, Franklin RJ, (2015) Vitamin D receptor-retinoid $\mathrm{X}$ receptor heterodimer signaling regulates oligodendrocyte progenitor cell differentiation. J Cell Biol 211(5):975-985

88. Ulven SM, Natarajan V, Holven KB, Løvdal T, Berg T, Blomhoff R (1998) Expression of retinoic acid receptor and retinoid $\mathrm{X}$ receptor subtypes in rat liver cells: implications for retinoid signalling in parenchymal, endothelial, Kupffer and stellate cells. Eur J Cell Biol 77(2):111-116

89. Yang T, Michele DE, Park J, Smart AM, Lin Z, Brosius FC III, Schnermann JB, Briggs JP (1999) Expression of peroxisomal proliferator-activated receptors and retinoid $\mathrm{X}$ receptors in the kidney. Am J Physiol Renal Physiol 277:F966-F973

90. Wang J, Swartz-Basile DA, Rubin DC, Levin MS (1997) Retinoic acid stimulates early cellular proliferation in the adapting remnant rat small intestine after partial resection. J Nutr 127:1297-1303

91. Subbarayan V, Mark M, Messadeq N, Rustin P, Chambon P, Kastner P (2000) RXR $\alpha$ overexpression in cardiomyocytes causes dilated cardiomyopathy but fails to rescue myocardial hypoplasia in RXR $\alpha$-null fetuses. J Clin Investig 105(3):387-394

92. Fritsche J, Stonehouse TJ, Katz DR, Andreesen R, Kreutz M (2000) Expression of retinoid receptors during human monocyte differentiation in vitro. Biochem Biophys Res Commun 270(1):17-22

93. Sugii S, Olson P, Sears DD, Saberi M, Atkins AR, Barish GD, Hong S-H, Castro GL, Yin Y-Q, Nelson MC (2009) PPAR $\gamma$ activation in adipocytes is sufficient for systemic insulin sensitization. Proc Natl Acad Sci 106(52):22504-22509

94. Ruan H, Zhan Y, Hou J, Xu B, Chen B, Tian Y, Wu D, Zhao Y, Zhang Y, Chen X (2017) Berberine binds RXR $\alpha$ to suppress $\beta$-catenin signaling in colon cancer cells. Oncogene 36(50):6906-6918

95. Aranda A, Pascual A (2001) Nuclear hormone receptors and gene expression. Physiol Rev 81(3):1269-1304. https://doi.org/ 10.1152/physrev.2001.81.3.1269
96. Yu X, Shao X-G, Sun H, Li Y-N, Yang J, Deng Y-C, Huang Y-G (2008) Activation of cerebral peroxisome proliferator-activated receptors gamma exerts neuroprotection by inhibiting oxidative stress following pilocarpine-induced status epilepticus. Brain Res 1200:146-158

97. Paradis É, Clavel S, Bouillaud F, Ricquier D, Richard D (2003) Uncoupling protein 2: a novel player in neuroprotection. Trends Mol Med 9(12):522-525

98. Zhang J, Götz S, Weisenhorn DMV, Simeone A, Wurst W, Prakash N (2015) A WNT1-regulated developmental gene cascade prevents dopaminergic neurodegeneration in adult En1+/mice. Neurobiol Dis 82:32-45

99. Xu Z, Jiang H, Zhong P, Yan Z, Chen S, Feng J (2016) Direct conversion of human fibroblasts to induced serotonergic neurons. Mol Psychiatry 21(1):62-70

100. Dickey AS, Sanchez DN, Arreola M, Sampat KR, Fan W, Arbez N, Akimov S, Van Kanegan MJ, Ohnishi K, Gilmore-Hall SK (2017) PPAR $\delta$ activation by bexarotene promotes neuroprotection by restoring bioenergetic and quality control homeostasis. Science Translational Medicine 9 (419)

101. Zapata-Gonzalez F, Rueda F, Petriz J, Domingo P, Villarroya F, De Madariaga A, Domingo JC (2007) 9-cis-Retinoic acid (9cRA), a retinoid X receptor (RXR) ligand, exerts immunosuppressive effects on dendritic cells by RXR-dependent activation: inhibition of peroxisome proliferator-activated receptor $\gamma$ blocks some of the 9cRA activities, and precludes them to mature phenotype development. J Immunol 178(10):6130-6139

102. Nagy L, Szanto A, Szatmari I, Széles L (2012) Nuclear hormone receptors enable macrophages and dendritic cells to sense their lipid environment and shape their immune response. Physiol Rev 92(2):739-789

103. Saijo K, Winner B, Carson CT, Collier JG, Boyer L, Rosenfeld MG, Gage FH, Glass CK (2009) A Nurr1/CoREST pathway in microglia and astrocytes protects dopaminergic neurons from inflammation-induced death. Cell 137(1):47-59

104. Kiss M, Czimmerer Z, Nagy G, Bieniasz-Krzywiec P, Ehling M, Pap A, Poliska S, Boto P, Tzerpos P, Horvath A (2017) Retinoid $\mathrm{X}$ receptor suppresses a metastasis-promoting transcriptional program in myeloid cells via a ligand-insensitive mechanism. Proc Natl Acad Sci 114(40):10725-10730

105. Núñez V, Alameda D, Rico D, Mota R, Gonzalo P, Cedenilla M, Fischer T, Boscá L, Glass CK, Arroyo AG (2010) Retinoid $\mathrm{X}$ receptor $\alpha$ controls innate inflammatory responses through the up-regulation of chemokine expression. Proc Natl Acad Sci 107(23):10626-10631

106. Mukwaya A, Lennikov A, Xeroudaki M, Mirabelli P, Lachota M, Jensen L, Peebo B, Lagali N (2018) Time-dependent LXR/ RXR pathway modulation characterizes capillary remodeling in inflammatory corneal neovascularization. Angiogenesis 21(2):395-413

107. Xu J, Zhang Y, Xiao Y, Ma S, Liu Q, Dang S, Jin M, Shi Y, Wan B (2013) Inhibition of 12/15-lipoxygenase by baicalein induces microglia PPAR $\beta / \delta$ : a potential therapeutic role for CNS autoimmune disease. Cell Death Dis 4(4):e569-e569

108. Zuo Y, Huang L, Enkhjargal B, Xu W, Umut O, Travis ZD, Zhang G, Tang J, Liu F, Zhang JH (2019) Activation of retinoid $\mathrm{X}$ receptor by bexarotene attenuates neuroinflammation via PPAR $\gamma /$ SIRT6/FoxO3a pathway after subarachnoid hemorrhage in rats. J Neuroinflammation 16(1):1-15

109. Justin A, Mandal S, Prabitha P, Dhivya S, Yuvaraj S, Kabadi P, Sekhar SJ, Sandhya C, Wadhwani AD, Divakar S (2019) Rational design, synthesis, and in vitro neuroprotective evaluation of novel glitazones for PGC- $1 \alpha$ activation via PPAR- $\gamma$ : a new therapeutic strategy for neurodegenerative disorders. Neurotoxicity research:1-17 
110. Katsouri L, Lim YM, Blondrath K, Eleftheriadou I, Lombardero L, Birch AM, Mirzaei N, Irvine EE, Mazarakis ND, Sastre M (2016) PPAR $\gamma$-coactivator- $1 \alpha$ gene transfer reduces neuronal loss and amyloid- $\beta$ generation by reducing $\beta$-secretase in an Alzheimer's disease model. Proc Natl Acad Sci 113(43):12292-12297

111. Peng Y, Chen L, Qu Y, Wang D, Zhu Y, Zhu Y (2021) Rosiglitazone prevents autophagy by regulating Nrf2-antioxidant response element in a rat model of lithium-pilocarpine-induced status epilepticus. Neuroscience 455:212-222

112. Hong S, Xin Y, HaiQin W, GuiLian Z, Ru Z, ShuQin Z, HuQing W, Li Y, Yun D (2012) The PPAR $\gamma$ agonist rosiglitazone prevents cognitive impairment by inhibiting astrocyte activation and oxidative stress following pilocarpine-induced status epilepticus. Neurol Sci 33(3):559-566

113. Polvani S, Tarocchi M, Galli A (2012) PPAR $\gamma$ and oxidative stress: Con ( $\beta$ ) catenating NRF2 and FOXO. PPAR research 2012

114. Eslami H, Sharifi AM, Rahimi H, Rahati M (2014) Protective effect of telmisartan against oxidative damage induced by high glucose in neuronal PC12 cell. Neurosci Lett 558:31-36

115. Hwang J, Kleinhenz DJ, Lassègue B, Griendling KK, Dikalov S, Hart CM (2005) Peroxisome proliferator-activated receptor- $\gamma$ ligands regulate endothelial membrane superoxide production. Am J Physiol Cell Physiol 288(4):C899-C905

116. Villa GR, Hulce JJ, Zanca C, Bi J, Ikegami S, Cahill GL, Gu Y, Lum KM, Masui K, Yang H (2016) An LXR-cholesterol axis creates a metabolic co-dependency for brain cancers. Cancer Cell 30(5):683-693

117. Széles L, Póliska S, Nagy G, Szatmari I, Szanto A, Pap A, Lindstedt M, Santegoets SJ, Rühl R, Bz D (2010) Research resource: transcriptome profiling of genes regulated by RXR and its permissive and nonpermissive partners in differentiating monocytederived dendritic cells. Mol Endocrinol 24(11):2218-2231

118. Szatmari I, Töröcsik D, Agostini M, Nagy T, Gurnell M, Barta E, Chatterjee K, Nagy L (2007) PPAR $\gamma$ regulates the function of human dendritic cells primarily by altering lipid metabolism. Blood, The Journal of the American Society of Hematology 110(9):3271-3280

119. Nishimaki-Mogami T, Tamehiro N, Sato Y, Okuhira K-i, Sai K, Kagechika H, Shudo K, Abe-Dohmae S, Yokoyama S, Ohno Y (2008) The RXR agonists PA024 and HX630 have different abilities to activate LXR/RXR and to induce ABCA1 expression in macrophage cell lines. Biochem Pharmacol 76(8):1006-1013

120. Jessup W, Gelissen IC, Gaus K, Kritharides L (2006) Roles of ATP binding cassette transporters A1 and G1, scavenger receptor BI and membrane lipid domains in cholesterol export from macrophages. Curr Opin Lipidol 17(3):247-257

121. Hirsch-Reinshagen V, Maia LF, Burgess BL, Blain J-F, Naus KE, McIsaac SA, Parkinson PF, Chan JY, Tansley GH, Hayden MR (2005) The absence of ABCA1 decreases soluble ApoE levels but does not diminish amyloid deposition in two murine models of Alzheimer disease. J Biol Chem 280(52):43243-43256

122. Wolf A, Bauer B, Hartz A (2012) ABC transporters and the Alzheimer's disease enigma. Front Psych 3:54

123. Meffre D, Hichor M, Gorgievski V, Tzavara ET, Trousson A, Ghoumari AM, Deboux C, Oumesmar BN, Liere P, Schumacher M (2015) Liver X receptors alpha and beta promote myelination and remyelination in the cerebellum. Proc Natl Acad Sci 112(24):7587-7592

124. Kidani Y, Bensinger SJ (2012) Liver X receptor and peroxisome proliferator-activated receptor as integrators of lipid homeostasis and immunity. Immunol Rev 249(1):72-83

125. Huang W, Ghisletti S, Saijo K, Gandhi M, Aouadi M, Tesz GJ, Zhang DX, Yao J, Czech MP, Goode BL (2011) Coronin
2A mediates actin-dependent de-repression of inflammatory response genes. Nature 470(7334):414-418

126. Fu Y, Zhen J, Lu Z (2017) Synergetic neuroprotective effect of docosahexaenoic acid and aspirin in SH-Y5Y by inhibiting miR-2 1 and activating RXR $\alpha$ and PPAR $\alpha$. DNA Cell Biol 36(6):482-489

127. Mark M, Ghyselinck NB, Chambon P (2006) Function of retinoid nuclear receptors: lessons from genetic and pharmacological dissections of the retinoic acid signaling pathway during mouse embryogenesis. Annu Rev Pharmacol Toxicol 46:451-480

128. Luria A, Furlow JD (2004) Spatiotemporal retinoid-X receptor activation detected in live vertebrate embryos. Proc Natl Acad Sci 101(24):8987-8992

129. Simandi Z, Horvath A, Cuaranta-Monroy I, Sauer S, Deleuze JF, Nagy L (2018) RXR heterodimers orchestrate transcriptional control of neurogenesis and cell fate specification. Mol Cell Endocrinol 471:51-62. https://doi.org/10.1016/j.mce.2017.07. 033

130. Baldassarro VA, Krezel W, Fernandez M, Schuhbaur B, Giardino L, Calza L (2019) The role of nuclear receptors in the differentiation of oligodendrocyte precursor cells derived from fetal and adult neural stem cells. Stem Cell Res 37:101443. https://doi.org/ 10.1016/j.scr.2019.101443

131. Keough MB, Yong VW (2013) Remyelination therapy for multiple sclerosis. Neurotherapeutics 10(1):44-54

132. Chang C-Z, Kwan A-L, Howng S-L (2010) 6-Mercaptopurine exerts an immunomodulatory and neuroprotective effect on permanent focal cerebral occlusion in rats. Acta Neurochir 152(8):1383-1390

133. Reno CM, Puente EC, Sheng Z, Daphna-Iken D, Bree AJ, Routh VH, Kahn BB, Fisher SJ (2017) Brain GLUT4 knockout mice have impaired glucose tolerance, decreased insulin sensitivity, and impaired hypoglycemic counterregulation. Diabetes 66(3):587-597

134. Gerhart DZ, Broderius MA, Borson ND, Drewes LR (1992) Neurons and microvessels express the brain glucose transporter protein GLUT3. Proc Natl Acad Sci 89(2):733-737

135. Armoni M, Harel C, Karnieli E (2007) Transcriptional regulation of the GLUT4 gene: from PPAR- $\gamma$ and FOXO1 to FFA and inflammation. Trends Endocrinol Metab 18(3):100-107

136. Ahuja HS, Liu S, Crombie DL, Boehm M, Leibowitz MD, Heyman RA, Depre C, Nagy L, Tontonoz P, Davies PJ (2001) Differential effects of rexinoids and thiazolidinediones on metabolic gene expression in diabetic rodents. Mol Pharmacol 59(4):765-773

137. Emilsson V, O’Dowd J, Wang S, Liu Y-L, Sennitt M, Heyman $\mathrm{R}$, Cawthorne MA (2000) The effects of rexinoids and rosiglitazone on body weight and uncoupling protein isoform expression in the Zucker fa/fa rat. Metabolism-Clinical and Experimental 49(12):1610-1615

138. Mulder P, Morrison MC, Verschuren L, Liang W, van Bockel JH, Kooistra T, Wielinga PY, Kleemann R (2016) Reduction of obesity-associated white adipose tissue inflammation by rosiglitazone is associated with reduced non-alcoholic fatty liver disease in LDLr-deficient mice. Sci Rep 6(1):1-11

139. Natrajan MS, de la Fuente AG, Crawford AH, Linehan E, Nunez V, Johnson KR, Wu T, Fitzgerald DC, Ricote M, Bielekova B (2015) Retinoid X receptor activation reverses age-related deficiencies in myelin debris phagocytosis and remyelination. Brain 138(12):3581-3597

140. Risner ML, Pasini S, Cooper ML, Lambert WS, Calkins DJ (2018) Axogenic mechanism enhances retinal ganglion cell excitability during early progression in glaucoma. Proc Natl Acad Sci 115(10):E2393-E2402 
141. Mascrez B, Ghyselinck NB, Chambon P, Mark M (2009) A transcriptionally silent $\mathrm{RXR} \alpha$ supports early embryonic morphogenesis and heart development. Proc Natl Acad Sci 106(11):4272-4277

142. Mirzaei M, Gupta VB, Chick JM, Greco TM, Wu Y, Chitranshi N, Vander Wall R, Hone E, Deng L, Dheer YJSr (2017) Agerelated neurodegenerative disease associated pathways identified in retinal and vitreous proteome from human glaucoma eyes. 7 (1): $1-16$

143. Eidet JR, Jørstad ØK, Fostad IG, Olstad OK, Sørland RØ, Moe MC, Petrovski G, Pepaj MJJoOI, Infection (2020) Unilateral acute anterior uveitis is associated with ipsilateral changes in the tear fluid proteome that involves the LXR/RXR pathway. $10: 1-8$

144. Sharma S, Bollinger KE, Kodeboyina SK, Zhi W, Patton J, Bai S, Edwards B, Ulrich L, Bogorad D, Sharma A (2018) Proteomic alterations in aqueous humor from patients with primary open angle glaucoma. Invest Ophthalmol Vis Sci 59(6):2635-2643. https://doi.org/10.1167/iovs.17-23434

145. Hsieh C, Pei D, Hung Y, Hsiao F (2011) Association between retinoid-X receptor-gamma genetic polymorphisms and diabetic retinopathy. Genet Mol Res 10(4):3545-3551

146. Luo X, Yu C, Fu C, Shi W, Wang X, Zeng C, Wang H (2015) Identification of the differentially expressed genes associated with familial combined hyperlipidemia using bioinformatics analysis. Mol Med Rep 11(6):4032-4038

147. Moutinho M, Codocedo JF, Puntambekar SS, Landreth GE (2019) Nuclear receptors as therapeutic targets for neurodegenerative diseases: lost in translation. Annu Rev Pharmacol Toxicol 59:237-261

148. Cummings JL, Zhong K, Kinney JW, Heaney C, Moll-Tudla J, Joshi A, Pontecorvo M, Devous M, Tang A, Bena J (2016) Double-blind, placebo-controlled, proof-of-concept trial of bexarotene in moderate Alzheimer's disease. Alzheimer's research \& therapy $8(1): 1-9$

149. Tachibana M, Shinohara M, Yamazaki Y, Liu C-C, Rogers J, Bu G, Kanekiyo T (2016) Rescuing effects of RXR agonist bexarotene on aging-related synapse loss depend on neuronal LRP1. Exp Neurol 277:1-9

150. Wang W, Nakashima K-i, Hirai T, Inoue M (2019) Anti-inflammatory effects of naturally occurring retinoid $\mathrm{X}$ receptor agonists isolated from Sophora tonkinensis Gagnep. via retinoid X receptor/liver X receptor heterodimers. Journal of natural medicines 73 (2):419-430

151. Koldamova R, Lefterov I (2007) Role of LXR and ABCA1 in the pathogenesis of Alzheimer's disease-implications for a new therapeutic approach. Curr Alzheimer Res 4(2):171-178

152. Kawahara K, Suenobu M, Ohtsuka H, Kuniyasu A, Sugimoto Y, Nakagomi M, Fukasawa H, Shudo K, Nakayama H (2014) Cooperative therapeutic action of retinoic acid receptor and retinoid $\mathrm{x}$ receptor agonists in a mouse model of Alzheimer's disease. $\mathrm{J}$ Alzheimers Dis 42(2):587-605

153. Sun Y, Fan J, Zhu Z, Guo X, Zhou T, Duan W, Shen X (2015) Small molecule TBTC as a new selective retinoid $X$ receptor $\alpha$ agonist improves behavioral deficit in Alzheimer's disease model mice. Eur J Pharmacol 762:202-213

154. Bonet-Costa V, Herranz-Perez V, Blanco-Gandia M, MasBargues C, Ingles M, Garcia-Tarraga P, Rodriguez-Arias M, Minarro J, Borras C, Garcia-Verdugo JM (2016) Clearing amyloid- $\beta$ through PPAR $\gamma / \mathrm{ApoE}$ activation by genistein is a treatment of experimental Alzheimer's disease. J Alzheimers Dis 51(3):701-711

155. Ghosal K, Haag M, Verghese PB, West T, Veenstra T, Braunstein JB, Bateman RJ, Holtzman DM, Landreth GE (2016) A randomized controlled study to evaluate the effect of bexarotene on amyloid-beta and apolipoprotein E metabolism in healthy subjects. Alzheimers Dement (N Y) 2(2):110-120. https://doi. org/10.1016/j.trci.2016.06.001

156. Bachmeier C, Beaulieu-Abdelahad D, Crawford F, Mullan M, Paris D (2013) Stimulation of the retinoid X receptor facilitates beta-amyloid clearance across the blood-brain barrier. J Mol Neurosci 49(2):270-276

157. DeMaagd G, Philip AJP, therapeutics (2015) Parkinson's disease and its management: part 1: disease entity, risk factors, pathophysiology, clinical presentation, and diagnosis. 40 (8):504

158. Chinta SJ, Andersen JKJTijob, biology c (2005) Dopaminergic neurons. 37 (5):942-946

159. Friling S, Bergsland M, Kjellander S (2009) Activation of retinoid $\mathrm{X}$ receptor increases dopamine cell survival in models for Parkinson's disease. BMC Neurosci 10:146. https://doi.org/10. 1186/1471-2202-10-146

160. Saucedo-Cardenas O, Quintana-Hau JD, Le W-D, Smidt MP, Cox JJ, De Mayo F, Burbach JPH, Conneely OM (1998) Nurr1 is essential for the induction of the dopaminergic phenotype and the survival of ventral mesencephalic late dopaminergic precursor neurons. Proc Natl Acad Sci 95(7):4013-4018

161. Wang J, Bi W, Zhao W, Varghese M, Koch RJ, Walker RH, Chandraratna RA, Sanders ME, Janesick A, Blumberg B, Ward L, Ho L, Pasinetti GM (2016) Selective brain penetrable Nurr1 transactivator for treating Parkinson's disease. Oncotarget 7(7):74697479. https://doi.org/10.18632/oncotarget.7191

162. Stefanis L (2012) $\alpha$-Synuclein in Parkinson's disease. Cold Spring Harbor perspectives in medicine 2 (2):a009399

163. Davidi D, Schechter M, Elhadi SA, Matatov A, Nathanson L, Sharon R (2020) Alpha-synuclein translocates to the nucleus to activate retinoic-acid-dependent gene transcription. iScience 23(3):100910. https://doi.org/10.1016/j.isci.2020.100910

164. Campos-Melo D, Galleguillos D, Sánchez N, Gysling K, Andrés ME (2013) Nur transcription factors in stress and addiction. Front Mol Neurosci 6:44

165. Lévesque D, Rouillard C (2007) Nur77 and retinoid X receptors: crucial factors in dopamine-related neuroadaptation. Trends Neurosci 30(1):22-30

166. Ishiguro H, Okubo Y, Ohtsuki T, Yamakawa-Kobayashi K, Arinami T (2002) Mutation analysis of the retinoid X receptor beta, nuclear-related receptor 1 , and peroxisome proliferator-activated receptor alpha genes in schizophrenia and alcohol dependence: possible haplotype association of nuclear-related receptor 1 gene to alcohol dependence. Am J Med Genet 114(1):15-23

167. Weiner HL (2009) The challenge of multiple sclerosis: how do we cure a chronic heterogeneous disease? Annals of Neurology: Official Journal of the American Neurological Association and the Child Neurology Society 65(3):239-248

168. Lassmann H, Ransohoff RM (2004) The CD4-Th1 model for multiple sclerosis: a crucial re-appraisal. Trends Immunol 25(3):132-137

169. Di Canio L (2019) Regulation of oligodendrocyte lineage cell function by the RXR $\gamma$ nuclear receptor. University of Cambridge,

170. Chandraratna RA, Noelle RJ, Nowak EC (2016) Treatment with retinoid X receptor agonist IRX4204 ameliorates experimental autoimmune encephalomyelitis. American journal of translational research 8(2):1016

171. Yang X-H, Ding Y, Li W, Zhang R-Y, Wu J-L, Ling E-A, Wu W, Zeng Y-s (2017) Effects of electroacupuncture and the retinoid $\mathrm{X}$ receptor (RXR) signalling pathway on oligodendrocyte differentiation in the demyelinated spinal cord of rats. Acupunct Med 35(2):122-132

172. Huang JK, Franklin RJ (2011) Regenerative medicine in multiple sclerosis: identifying pharmacological targets of adult neural stem cell differentiation. Neurochem Int 59(3):329-332 
173. Xu J, Drew PD (2006) 9-Cis-retinoic acid suppresses inflammatory responses of microglia and astrocytes. J Neuroimmunol 171(1-2):135-144

174. Nowak E, Chandraratna R, Noelle R (2016) Treatment with the retinoid X receptor agonist IRX4204 ameliorates active and passive experimental autoimmune encephalomyelitis in mice (P5. 315). AAN Enterprises,

175. Gaunt CM, Rainbow D, Mackenzie R, Jarvis L, Mousa H, Cunniffe N, Georgieva Z, Brown W, Coles A, Jones JL (2021) The MS remyelinating drug bexarotene (an RXR agonist) promotes induction of human Tregs and suppresses Th17 differentiation in vitro. bioRxiv

176. Mielcarz D, Bergeron A, DeLong J, Andreozzi R, Nowak E, Chandraratna R, Sanders M, Noelle R, Channon J (2016) The retinoid X receptor (RXR) selective agonist IRX4204 promotes differentiation of human Treg cells and inhibits differentiation of human TH17 cells (P5. 272). AAN Enterprises,

177. Loppi S, Kolosowska N, Kärkkäinen O, Korhonen P, Huuskonen M, Grubman A, Dhungana H, Wojciechowski S, Pomeshchik Y,
Giordano M (2018) HX600, a synthetic agonist for RXR-Nurr1 heterodimer complex, prevents ischemia-induced neuronal damage. Brain Behav Immun 73:670-681

178. Sanders M, Chandraratna R, Marek K, Jennings D (2016) A phase 1 clinical study of the retinoid $X$ receptor (RXR) selective agonist IRX4204 in patients with early Parkinson's disease (PD) (P2. 342). AAN Enterprises,

179. Krezel W, Dupe V, Mark M, Dierich A, Kastner P, Chambon P (1996) RXR gamma null mice are apparently normal and compound RXR alpha +/-/RXR beta -/-/RXR gamma -/- mutant mice are viable. Proc Natl Acad Sci U S A 93(17):9010-9014. https:// doi.org/10.1073/pnas.93.17.9010

Publisher's Note Springer Nature remains neutral with regard to jurisdictional claims in published maps and institutional affiliations. 